\title{
Verification of AP1000 ${ }^{\circledR}$ low-margin PRA sequences based on best-estimate calculations
}

\author{
C. Queral*, J. Montero-Mayorga, J. Rivas-Lewicky, M.J. Rebollo \\ Universidad Politécnica de Madrid, Calle Alenza 4, 28003 Madrid, Spain
}

\begin{abstract}
A B S T R A C T
The Westinghouse $\mathbf{A P 1 0 0 0}{ }^{\circledR}$ reactor is an advanced design whose safety systems are mainly passive safety systems. Due to the passive nature of the safety related systems and its dependency on small changes on certain variables (e.g. pressure, friction coefficients) together with the use of a simplified code like MAAP in Probabilistic Risk Assessment (PRA) analyses, it makes necessary to confirm that when core cooling is achieved, thermal-hydraulic $(\mathrm{T} / \mathrm{H})$ uncertainties are bounded. The $\mathrm{T} / \mathrm{H}$ uncertainty evaluation process performed by Westinghouse Electric Company (WEC) identified the low-margin sequences (core uncovery) by expanding PRA Event Trees (ETs). The expanded ETs allowed finding the low-margin riskimportant sequences and then a set of low-margin bounding sequences was selected. Then detailed safety analysis methodologies were applied in order to evaluate the bounding sequences demonstrating that the $\mathrm{T} / \mathrm{H}$ uncertainties were bounded. The Universidad Politécnica de Madrid group has verified the low-margin bounding sequences obtained by WEC with the best-estimate TRACE code in order to verify the previous results and also to study the phenomenology of such sequences through a best-estimate code. This paper presents the results obtained for short-term low-margin bounding sequences. In general, TRACE results do not present important discrepancies with respect to NOTRUMP and WCOBRA/TRAC results although TRACE presents lower values for Peak Cladding Temperature. This analysis has allowed to verify the AP1000 thermal-hydraulic bounding evaluation process performed by WEC for the lowmargin risk-important sequences with TRACE code.
\end{abstract}

\section{Introduction}

The success criteria justification in the AP1000 Probabilistic Risk Assessment (PRA) was addressed, in part, through the analysis performed in the Deterministic Safety Analysis (DSA) as part of the Design Control Document (DCD) (Westinghouse Electric Company, 2008) but in sequences which involved Automatic Depressurization System (ADS) actuation, (e.g. small break LOCA) the DSA

Abbreviations: ACC, Accumulator; ADS, Automatic Depressurization System; BE, Best-Estimate; BS, Bounding Sequence; CDF, Core Damage Frequency; CMT, Core Make-up Tank; DSA, Deterministic Safety Analysis; DVI, Direct Vessel Injection; DVILB, Direct Vessel Injection Line Break; EET, Expanded Event Tree; ET, Event Tree; IAEA, International Atomic Energy Agency; IRWST, In Containment Refueling Water Storage Tank; LM, Low Margin sequence; LOCA, Loss of Coolant Accident; LRF, Large Release Frequency; NRC, Nuclear Regulatory Commission; PCT, Peak Cladding Temperature; PRA, Probabilistic Risk Assessment; PRHR, Passive Residual Heat Removal; PWR, Pressurized Water Reactor; PZR, Pressurizer; RCS, Reactor Coolant System; SSG, Specific Safety Guide; T/H, Thermal Hydraulic; WEC, Westinghouse Electric Company.

* Corresponding author.

E-mail address: cesar.queral@upm.es (C. Queral).
Thermal-Hydraulic $(\mathrm{T} / \mathrm{H})$ analysis was not applicable due to the assumption of single failure in such analyses. This fact leads to the performance of a large number of simulations due to the multiple combinations between events and failure combinations. These analyses are only feasible if fast computer codes are used. Therefore, MAAP4 code (MAAP4, 1994) was selected for this purpose, see (Westinghouse Electric Company, 2003b). This issue was a licensing problem since the NRC required a more detailed analysis in order to bound the potential $\mathrm{T} / \mathrm{H}$ uncertainties associated to the use of best-estimate parameter values (e.g. residual heat) and the limited details and simplified TH models included in MAAP code (Selim Sancaktar and Terry Schulz, 2004).

In order to cope with this issue, Westinghouse Electric Company (WEC) developed an approach to bound the T/H uncertainty in the AP600 PRA success criteria analysis which was also applied to the AP1000, see references (Selim Sancaktar and Terry Schulz, 2004; Ohkawa et al., 1997; Westinghouse Electric Company, 2003a; Advisory Committee on Reactor safeguards subcommittees on Reliability and probabilistic Risk Assessment, 2003). This approach must demonstrate that the low margin 
sequences (core uncovery sequences) which have been considered as success sequences in PRA are bounded by $\mathrm{T} / \mathrm{H}$ uncertainties.

The methodology developed by WEC identified the low-margin sequences by expanding PRA Event Trees (ET). The expanded ETs allowed to find the low-margin risk-important sequences and then a set of low-margin bounding sequences was selected. Then detailed safety analysis methodologies were applied in order to evaluate the bounding sequences. Several DSA methodologies corresponding to different options of the IAEA Specific Safety Guide SSG-2, see Table 1 and (IAEA, 2009), were applied by WEC to evaluate each low-margin bounding sequence.

The main goal of this work is to reproduce and verify the whole bounding process proposed by WEC including the simulation of all short-term low-margin bounding sequences applying the SSG-2 option 2 methodology.

This work has been developed in the frame of the "Integrated Safety Analysis Methodology Applied to Advanced Reactors (ISAMAR)" project. The ISAMAR project includes several DSA and PRA verifications like LBLOCA-BEPU (DSA), SBLOCA (DSA), Direct Vessel Injection Line Break (DVILB) ET delineation (PRA) and available time in DVILB sequences, see (Montero-Mayorga et al., 2015, 2014; Queral et al., 2015; Queral and Montero-Mayorga, 2016).

In the sequel, Section 2 presents the AP1000 passive safety systems. Section 3 provides a description of low-margin sequences evaluation process. Section 4 gives an overview about LOCA sequences in the AP1000 reactor and the AP1000 TRACE model nodalization is presented in Section 5. The analysis of lowmargin bounding sequences as well as main results obtained is presented in Section 6. Finally, Section 7 collects the main conclusions of this paper.

\section{AP1000 passive safety systems}

Basically, the same configuration of typical PWRs safety systems is used for AP1000, one system for high pressure safety injection (CMTs), one system for medium pressure safety injection (accumulators) and one system for low pressure safety injection (IRWST). However, these systems are significantly simpler than typical PWR safety systems since they contain significantly fewer components. In addition a new system for passive core cooling is implemented (PRHR) as well as one system for ADS. Figs. 1 and 2 show a schematic view of AP1000 reactor and the main systems. The AP1000 passive safety systems are briefly described below (Westinghouse Electric Company, 2008):

- Core Makeup Tanks (CMTs). There are two CMTs as part of the passive safety system in AP1000. These tanks are cylindrical with an hemispherical upper and lower head. The CMTs are located above the Direct Vessel Injection (DVI), Fig. 1, and they are filled with cold $(\approx 320 \mathrm{~K})$ borated water at the Reactor Coolant System (RCS) pressure. Each tank $\left(70.8 \mathrm{~m}^{3}\right)$ is connected to one cold leg of the same loop from the upper part and to the DVI

Table 1

Options for DSA methodologies, IAEA Specific Safety Guide SSG-2, (IAEA, 2009).

\begin{tabular}{clll}
\hline Option & $\begin{array}{l}\text { Computer } \\
\text { code }\end{array}$ & Availability of systems & $\begin{array}{l}\text { Initial and boundary } \\
\text { conditions }\end{array}$ \\
\hline 1 & Conservative & Conservative assumptions & $\begin{array}{l}\text { Conservative input } \\
\text { data } \\
\text { Conservative input } \\
\text { data } \\
\text { Realistic input data } \\
\text { with uncertainties } \\
\text { Realistic input data } \\
\text { with uncertainties }\end{array}$ \\
4 & BE & BE & Conservative assumptions \\
\hline & BE & $\begin{array}{l}\text { Probabilistic safety } \\
\text { analysis based } \\
\text { assumptions }\end{array}$ & \\
\hline
\end{tabular}

from the lower part. In normal operation the balance line (connection from the RCS to the upper part of the CMT) is normally open. However, the discharge of the CMTs is isolated upon receipt a safeguards signal $\mathbf{S}$. In case of demand, the CMTs can operate in two different ways, injection and recirculation modes.

- Accumulators (ACCS). As in a standard PWR the AP1000 includes ACCs as well. There are 2 spherical ACCs ( $57 \mathrm{~m}^{3}$ each) located just below the CMTs and are filled with borated water $(\approx 320 \mathrm{~K})$ and pressurized with nitrogen (49 bar). Like the CMTs, the ACCs are connected to the DVI lines. In normal operation the ACCs are isolated by check valves. If the RCS pressure falls below the ACCs pressure, the check valves open. The ACCs are necessary in order to reflood the core in case of LOCA providing borated water at high flow.

- In Containment Refueling Water Storage Tank (IRWST). The IRWST is a large tank $\left(2070 \mathrm{~m}^{3}\right)$ located inside the containment and above the RCS. Two lines connect the lower part of the IRWST with both DVI lines. The borated water $(\approx 320 \mathrm{~K})$ inside the IRWST will drain by gravity into the RCS when the pressure is close to the containment pressure.

- Passive Residual Heat Removal System (PRHR). The passive core cooling system includes a PRHR heat exchanger located inside the IRWST. The inlet of the system is connected to one of the hot legs at and the outlet is connected to the corresponding steam generator water box. The IRWST provides the heat sink for the PRHR with a water volume sufficient to absorb decay heat for more than one hour before the water begins to boil.

- Automatic Depressurization System (ADS). The ADS consists of four valves stages. It can be differentiated between the three first stages and the fourth one. Stages $1 / 2 / 3$ (ADS-1/2/3) consist of two lines each. Such lines are included as part of the PZR safety and relief valve module being connected to the top of the PZR. The discharge of these valves is located inside the IRWST. On the other hand, stage-4 (ADS-4) has four lines connected to the hot legs which discharges directly to the containment. The whole system accounts for a total of 20 valves: ADS- 1 is composed by 4-inch motor-operated valves, ADS-2/3 are 8inch motor-operated valves and ADS- 4 is composed by 14 inch squib valves.

\section{Low-margin sequences evaluation process}

This section describes the methodology followed by WEC to identify low-margin sequences (sequences with core uncovery) and thereafter, how such sequences are evaluated. This process must demonstrate that the low margin sequences which have been considered as success sequences in PRA are bounded by $\mathrm{T} / \mathrm{H}$ uncertainties. For this purpose, low-margin risk-important sequences must be determined and verified by means of thermal hydraulic analysis. The main steps of the WEC methodology are the following (Westinghouse Electric Company, 2003a), Fig. 3:

1. To delineate the Focused PRA (Selim Sancaktar and Terry Schulz, 2004). The Focused PRA is a sensitivity study of the AP1000 PRA which does not include active systems like the Normal Residual Heat Removal System for accident mitigation.

2. To expand the ETs of the Focused PRA. The expanded event trees (EET) include all the possible systems configuration and not only success criteria configurations are considered. For instance, the CMTs actuation possibilities in the standard ET are 1 out of 2 (success criteria) or zero, while in the EET the possibility of 2 out of 2 CMT actuation is also taken into account. 


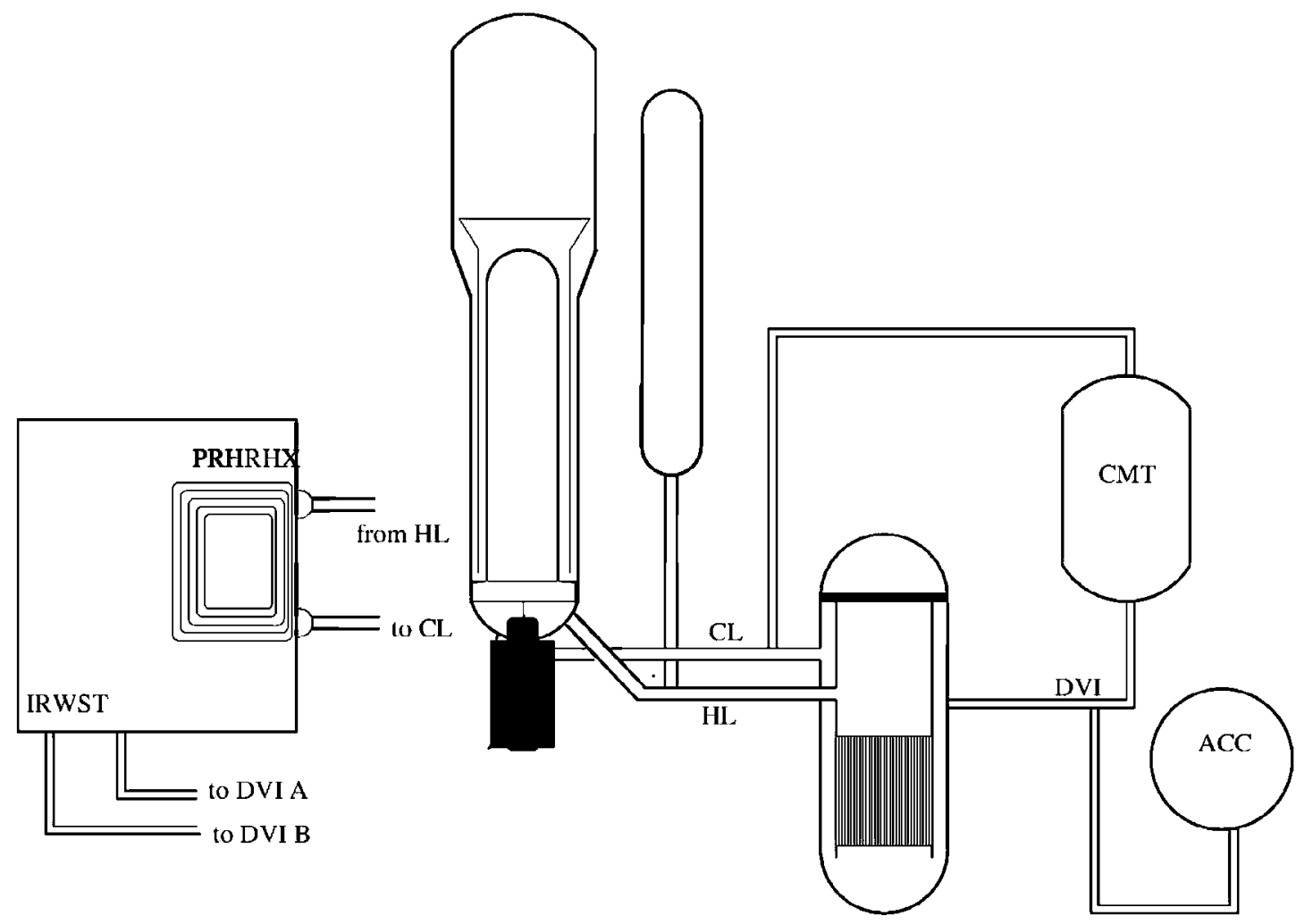

Fig. 1. AP1000 Elevation view.

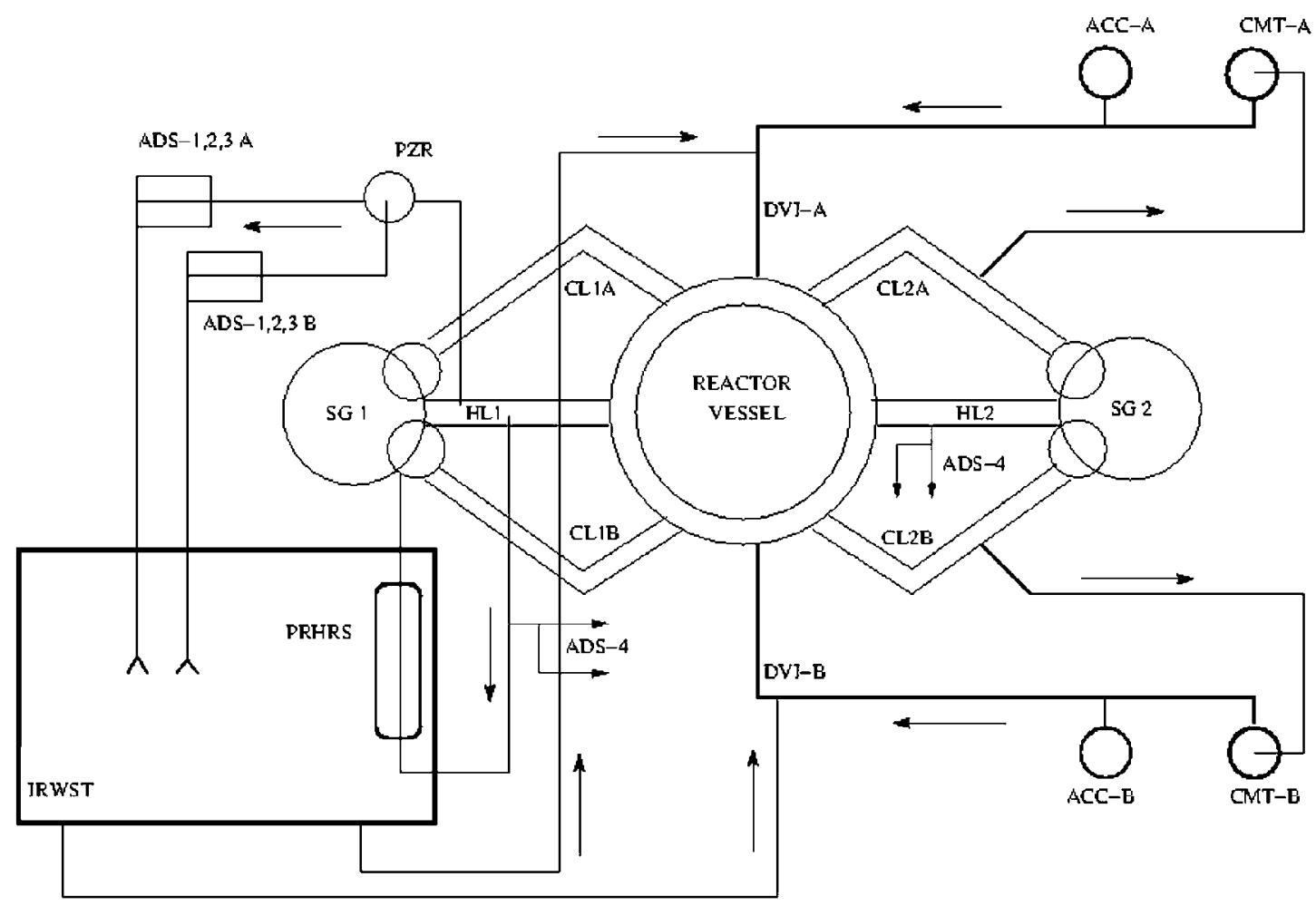

Fig. 2. AP1000 Plant view.

3. Once the expansion of the ET has been completed, the success sequences are binned into two categories:

- OK category which contains success sequences in which the core remains covered during the whole transient
- UC category which contains success sequences in which some core uncovery is detected (low-margin sequences).

4. The low-margin sequences are conservatively considered to lead to core damage in order to allow quantification of their 


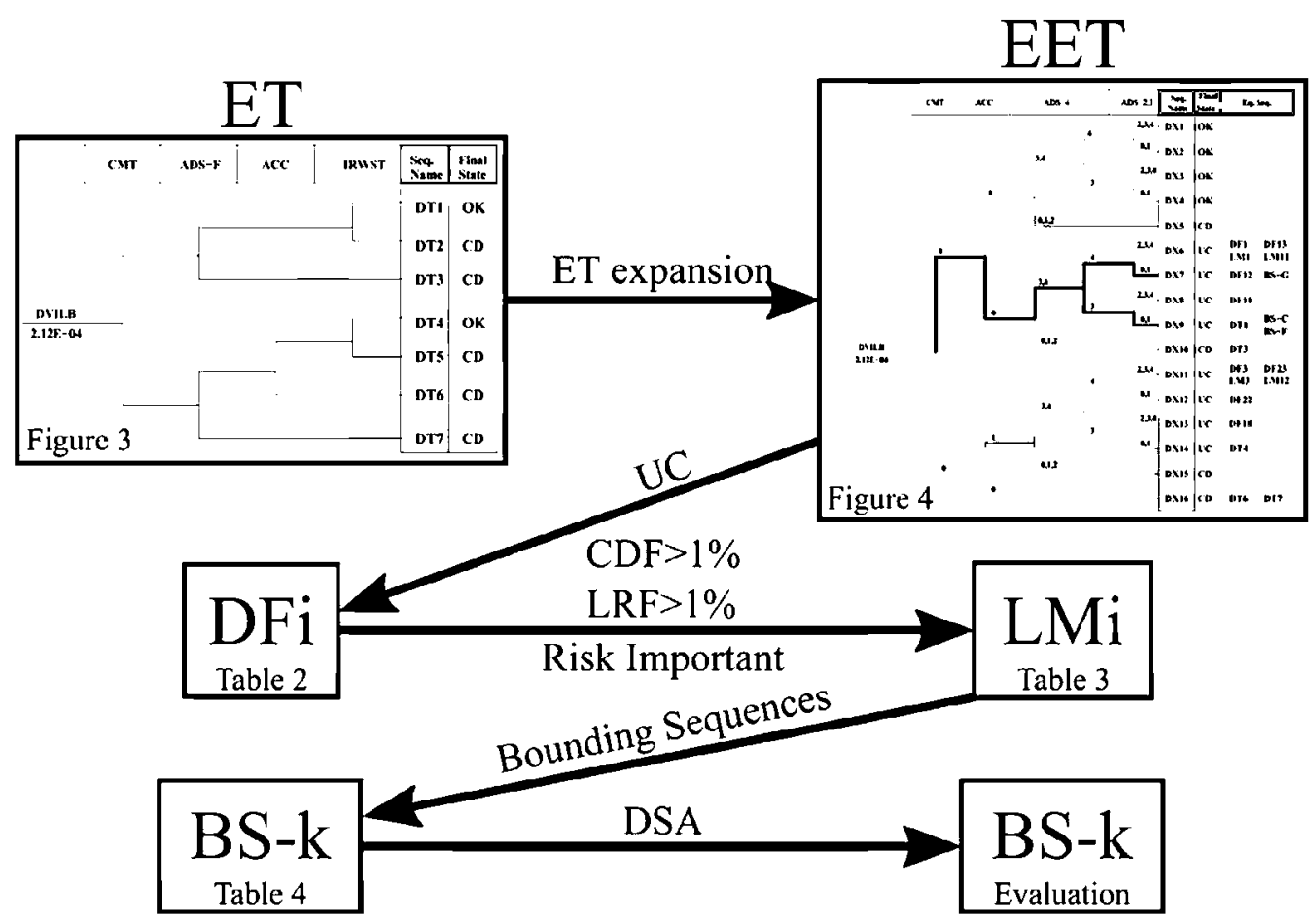

Fig. 3. Low-Margin Sequences Evaluation Process.

risk importance and are collected and ranked by their potential contributions to Core Damage Frequency (CDF) and Large Release Frequency (LRF), as shown in Table 2 (only the first 25 sequences have been collected for this paper from (Westinghouse Electric Company, 2003a), DFi sequences).

5. Only those sequences which can potentially contribute to the CDF or LRF with more than $1 \%$ of the base CDF or LRF are considered as low-margin risk-important sequences (LMi sequences), being the base CDF and LRF 2.41E-07/year and
1.95E-08/year, respectively (Westinghouse Electric Company, 2003b). WEC identified thirteen low-margin risk-important sequences which are gathered in Table 3 . It is important to remark that all these sequences correspond to different kinds of LOCA sequences. These low-margin risk-important sequences have the following characteristics in common (Westinghouse Electric Company, 2003a): 4 out of 4 ADS-4 valves and several of ADS-2/3 valves available; Six sequences have one tank (CMT or ACC) available; the remaining sequences

Table 2

PRA low-margin sequences sorted by potential CDF and LRF (DFi sequences) (Westinghouse Electric Company, 2003a).

\begin{tabular}{|c|c|c|c|c|c|c|c|c|c|c|c|c|}
\hline $\begin{array}{c}\text { DFi } \\
\text { Sequence }\end{array}$ & $\begin{array}{c}\text { Initiating } \\
\text { Event }\end{array}$ & $\begin{array}{l}\text { Sequence } \\
\text { CDF }\end{array}$ & $\begin{array}{l}\text { Sequence } \\
\text { LRF }\end{array}$ & $\begin{array}{l}\text { Percentage } \\
\text { CDF }\end{array}$ & $\begin{array}{l}\text { Percentage } \\
\text { LRF }\end{array}$ & CI & $\begin{array}{c}\text { IRWST } \\
\& \\
\text { RECIRC }\end{array}$ & CMT & ACC & ADS-4 & ADS- $2 / 3$ & $\begin{array}{l}\text { Bounding } \\
\text { Sequences }\end{array}$ \\
\hline DF1 & DVחB & $8.96 \mathrm{E}-07$ & $5.37 \mathrm{E}-08$ & 371.66 & 275.6 & Yes & Yes & 1 & 0 & 4 & $2-4$ & BS-C \\
\hline DF2 & SADS & $4.58 \mathrm{E}-07$ & $2.75 \mathrm{E}-08$ & 190.05 & 140.93 & Yes & Yes & 2 & 1 & 4 & $2-4$ & BS-E \\
\hline DF3 & DVLB & $3.05 \mathrm{E}-07$ & $1.83 \mathrm{E}-08$ & 126.76 & 94 & Yes & Yes & 0 & 1 & 4 & $2-4$ & BS-A \\
\hline DF4 & MBLOCA & $2.89 \mathrm{E}-07$ & $1.73 \mathrm{E}-08$ & 119.85 & 88.88 & Yes & Yes & 0 & 2 & 4 & $2-4$ & BS-A, BS-B \\
\hline DF5 & CMT & $1.34 \mathrm{E}-07$ & $8.05 \mathrm{E}-09$ & 55.67 & 41.28 & Yes & Yes & 0 & 2 & 4 & $2-4$ & BS-A, BS-B \\
\hline DF6 & SADS & $9.12 \mathrm{E}-08$ & $5.47 \mathrm{E}-09$ & 37.82 & 28.05 & No & Yes & 2 & 2 & 4 & $2-4$ & BS-E \\
\hline DF7 & MBLOCA & $3.01 \mathrm{E}-08$ & $1.81 \mathrm{E}-09$ & 12.48 & 9.26 & Yes & Yes & 2 & 0 & 4 & $2-4$ & BS-C \\
\hline DF8 & LBLOCA & $8.51 \mathrm{E}-09$ & 8, SIE-09 & 3.53 & 43.63 & No & Yes & 2 & 2 & 4 & $2-4$ & BS-D \\
\hline DF9 & CMT & $6.42 \mathrm{E}-09$ & $3.85 \mathrm{E}-10$ & 2.67 & 1.98 & Yes & Yes & 1 & 0 & 4 & $2-4$ & BS-C \\
\hline DF10 & MBLOCA & $2.44 \mathrm{E}-09$ & $1.47 \mathrm{E}-10$ & 1.01 & 0.75 & Yes & Yes & 0 & 1 & 4 & $2-4$ & BS-A \\
\hline DF11 & DVחB & $2.09 \mathrm{E}-09$ & $1.25 \mathrm{E}-10$ & 0.87 & 0.64 & Yes & Yes & 1 & 0 & 3 & $2-4$ & BS-C \\
\hline DF12 & DVIB & $1.64 \mathrm{E}-09$ & $9.83 \mathrm{E}-10$ & 0.68 & 0.5 & Yes & Yes & 1 & 0 & 4 & $0-1$ & BS-C \\
\hline DF13 & DVIB & $1.52 \mathrm{E}-09$ & $1.52 \mathrm{E}-09$ & 0.63 & 7.77 & No & Yes & 1 & 0 & 4 & $2-4$ & BS-C \\
\hline DF14 & CMT & $1.14 \mathrm{E}-09$ & $6.85 \mathrm{E}-11$ & 0.47 & 0.35 & Yes & Yes & 0 & 1 & 4 & $2-4$ & BS-A \\
\hline DF15 & SADS & $1.07 \mathrm{E}-09$ & $6.42 \mathrm{E}-11$ & 0.44 & 0.33 & Yes & Yes & 2 & 1 & 3 & $2-4$ & \\
\hline DF16 & SADS & $8.40 \mathrm{E}-10$ & $5.04 \mathrm{E}-11$ & 0.35 & 0.26 & Yes & Yes & 2 & 1 & 4 & $0-1$ & BS-E \\
\hline DF17 & SADS & $7.77 \mathrm{E}-10$ & $4.66 \mathrm{E}-11$ & 0.32 & 0.24 & No & Yes & 2 & 1 & 4 & $2-4$ & BS-E \\
\hline DF18 & $\begin{array}{l}\text { DVIB } \\
\end{array}$ & $7.21 \mathrm{E}-10$ & $4.32 \mathrm{E}-11$ & 0.3 & 0.22 & Yes & Yes & 0 & 1 & 3 & $2-4$ & \\
\hline DF19 & MBLOCA & $6.92 \mathrm{E}-10$ & $4.15 \mathrm{E}-11$ & 0.29 & 0.21 & Yes & Yes & 0 & 2 & 3 & $2-4$ & \\
\hline DF20 & SADS & $6.76 \mathrm{E}-10$ & $4,05 \mathrm{E}-11$ & 0.28 & 0.21 & Yes & Yes & 1 & 1 & 4 & $2-4$ & BS-E \\
\hline DF21 & MBLOCA & $6.44 \mathrm{E}-10$ & $3.86 \mathrm{E}-11$ & 0.27 & 0.2 & Yes & Yes & 0 & 2 & 4 & $0-1$ & BS-A, BS-B \\
\hline DF22 & DVILB & $6.15 \mathrm{E}-10$ & $3.69 \mathrm{E}-11$ & 0.26 & 0.19 & Yes & Yes & 0 & 1 & 4 & $0-1$ & BS-A \\
\hline DF23 & DVIB & $5.16 \mathrm{E}-10$ & $5.16 \mathrm{E}-10$ & 0.21 & 2.65 & No & Yes & 0 & 1 & 4 & $2-4$ & BS-A \\
\hline DF24 & MBLOCA & $4.88 \mathrm{E}-10$ & $4.88 \mathrm{E}-10$ & $\begin{array}{l}0.2 \\
\end{array}$ & 2.5 & No & Yes & 0 & 2 & 4 & $2-4$ & BS-A \\
\hline DF25 & CMT & $3.17 \mathrm{E}-10$ & $1.90 \mathrm{E}-11$ & 0.13 & 0.1 & Yes & Yes & 0 & 2 & 3 & $2-4$ & \\
\hline
\end{tabular}


Table 3

PRA low-margin risk-important sequences (LMi) (Westinghouse Electric Company, 2003a).

\begin{tabular}{|c|c|c|c|c|c|c|c|c|c|c|c|c|c|}
\hline $\begin{array}{c}\text { LMi } \\
\text { Sequence }\end{array}$ & $\begin{array}{c}\text { Initiating } \\
\text { event }\end{array}$ & CI & $\begin{array}{c}\text { IRWST } \\
\& \\
\text { RECIRC }\end{array}$ & CMT & $\mathrm{ACC}$ & $\begin{array}{c}\text { ADS- } \\
4\end{array}$ & ADS-2/3 & PRHR & CDF & LRF & $\% \mathrm{CDF}$ & $\%$ LRF & $\begin{array}{l}\text { Bounding } \\
\text { Sequence }\end{array}$ \\
\hline LM1 & DVILB & Yes & Yes & 1 & 0 & 4 & $2-4$ & $\mathrm{~N} / \mathrm{A}$ & $8.96 \mathrm{E}-07$ & $5.37 \mathrm{E}-08$ & 317.7 & 275.6 & BS-C \\
\hline LM2 & SADS & Yes & Yes & 2 & 1 & 4 & $2-4$ & N/A & $4.58 \mathrm{E}-07$ & $2.75 \mathrm{E}-08$ & 190.1 & 140.9 & BS-E \\
\hline LM3 & DVILB & Yes & Yes & 0 & 1 & 4 & $2-4$ & Yes & $3.05 \mathrm{E}-07$ & $1.83 \mathrm{E}-08$ & 126.8 & 94 & BS-A \\
\hline LM4 & MBLOCA & Yes & Yes & 0 & 2 & 4 & $2-4$ & Yes & $2.89 \mathrm{E}-07$ & $1.73 \mathrm{E}-08$ & 119.9 & 88.9 & BS-B \\
\hline LM5 & CMT & Yes & Yes & 0 & 2 & 4 & $2-4$ & Yes & $1.34 \mathrm{E}-07$ & $8.05 \mathrm{E}-09$ & 55.7 & 41.3 & BS-B \\
\hline LM6 & SADS & No & Yes & 2 & 2 & 4 & $2-4$ & N/A & $9.12 \mathrm{E}-08$ & $5.47 \mathrm{E}-09$ & 37.8 & 28 & BS-E \\
\hline LM7 & MBLOCA & Yes & Yes & 2 & 0 & 4 & $2-4$ & N/A & $3.01 \mathrm{E}-08$ & $1.81 \mathrm{E}-09$ & 12.5 & 9.3 & $\mathrm{BS}-\mathrm{C}$ \\
\hline LM8 & LBLOCA & No & Yes & 2 & 2 & 4 & $2-4$ & N/A & $8.51 \mathrm{E}-09$ & $8.51 \mathrm{E}-09$ & 3.5 & 43.6 & BS-D \\
\hline LM9 & CMT & Yes & Yes & 1 & 0 & 4 & $2-4$ & N/A & $6.42 \mathrm{E}-09$ & $3.85 \mathrm{E}-10$ & 2.7 & 2 & BS-C \\
\hline LM10 & MBLOCA & Yes & Yes & 0 & 1 & 4 & $2-4$ & Yes & $2.44 \mathrm{E}-09$ & $1.47 \mathrm{E}-10$ & 1,0 & 0.8 & BS-A \\
\hline LM11 & DVILB & No & Yes & 1 & 0 & 4 & $2-4$ & $\mathrm{~N} / \mathrm{A}$ & $1.52 \mathrm{E}-09$ & $1.52 \mathrm{E}-09$ & 0.6 & 7.8 & $\mathrm{BS}-\mathrm{C}$ \\
\hline LM12 & DVILB & $\mathrm{No}$ & Yes & 0 & 1 & 4 & $2-4$ & Yes & $5.16 \mathrm{E}-10$ & $5.16 \mathrm{E}-10$ & 0.2 & 2.6 & $\mathrm{BS}-\mathrm{A}$ \\
\hline LM13 & MBLOCA & $\mathrm{No}$ & Yes & 0 & 2 & 4 & $2-4$ & Yes & $4.88 \mathrm{E}-10$ & $4.88 \mathrm{E}-10$ & 0.2 & 2.5 & BS-A \\
\hline & & & & & & & Total $=$ & & $2.22 \mathrm{E}-06$ & $1.44 \mathrm{E}-07$ & & & \\
\hline
\end{tabular}

have two to four tanks (both ACCs and CMTs) available, The sequences without CMTs have the PRHR available (PRA success criteria).

6. Subsequently, five short-term and two long-term bounding sequences (BS-k) were selected by WEC to be analysed to bound the risk-important low-margin sequences, as shown in Table 4. None BS- $k$ sequence includes ADS-2/3 actuation in order to bound LMi sequences.

7. The final step of the WEC methodology is to evaluate such bounding sequences by using DSA methodologies, Table 1 , and the corresponding WEC T/H codes (NOTRUMP/LOCTA Meyer, 1985 and (Shimeck and Hartz, 2000), WCOBRA/TRAC (Hochreiter et al., 1998) to show if adequate core cooling is achieved and therefore $\mathrm{T} / \mathrm{H}$ uncertainties are bounded (Westinghouse Electric Company, 1997).

With respect to the DSA methodologies, it must be pointed out that, WEC follows SSG-2 option 3 methodology for bounding sequences BS-D and BS-E and SSG-2 option 1 methodology for the other bounding sequences, see (IAEA, 2009) for more details. The results obtained by WEC (last column in Table 4 ) show that are several short-term and long-term bounding sequences with core uncovery in MAAP simulations which did not present core uncovery with NOTRUMP.

The UPM group has reproduced the whole process for all the ETs proposed by WEC for potential expansion (Westinghouse Electric Company, 2003a): Medium break LOCA (MBLOCA), CMT line break (CMT), DVILB, LBLOCA and Spurious actuation of ADS (SADS). The first three ETs correspond to medium LOCA trees $(2$ in. $<D<9$ in.) and the last two ETs correspond to large LOCA. With this aim, the so called SSG-2 option 2 (IAEA, 2009) has been used to verify the low-margin bounding sequences, which includes the use of a best-estimate computer code (TRACE) US Nuclear Regulatory Commission, 2007. However, conservative initial conditions and assumptions are still used.

As an example, Figs. 4 and 5 show the ET expansion process for the DVILB initiating event reproduced by UPM. Furthermore, only sequences with successful injection of IRWST are considered since IRWST failure sequences are core damage sequences. Once the ETs have been expanded, different kind of sequences can be identified within them, Fig. 5:

- Sequences coming from the conventional ET (DTn).

- Sequences which conform the complete EET (DXm).

- Low-margin sequences with potential contribution to CDF or LRF, Table 2 (DFi).

Table 4

Low-margin bounding sequences identified by WEC (BS-k) (Westinghouse Electric Company, 2003a).

\begin{tabular}{|c|c|c|c|c|c|c|c|c|c|}
\hline $\begin{array}{l}\text { Bounding } \\
\text { sequence }\end{array}$ & Initiating event & $\mathbf{C I}$ & $\begin{array}{l}\text { IRWST \& } \\
\text { RECIRC }\end{array}$ & CMT & $\mathrm{ACC}$ & ADS-4 & PRHR & $\begin{array}{l}\text { Bounds LMi } \\
\text { Sequences }\end{array}$ & $\begin{array}{c}\text { PCT }(\mathrm{K}) \\
\text { NOTRUMP or } \\
\text { WCOBRA/TRAC }\end{array}$ \\
\hline \multicolumn{10}{|c|}{ Short-term Cooling } \\
\hline BS-A & Hot leg break (3.0 in.) & No & Yes & 0 & 1 & 4 & Yes & $3,10,12,13$ & $670(\mathrm{~N})$ \\
\hline BS-B & $\begin{array}{l}\text { Double-ended CMT } \\
\text { balance line }(6.8 \text { in. })\end{array}$ & Yes & Yes & 0 & 2 & 4 & Yes & 4,5 & $\begin{array}{l}\text { No core uncovery } \\
\text { (N) }\end{array}$ \\
\hline $\mathrm{BS}-\mathrm{C}$ & $\begin{array}{l}\text { Double-ended DVI } \\
\text { line }(4 \mathrm{in.})\end{array}$ & No & Yes & 1 & 0 & 3 & No & $1,7,9,11$ & $1127(\mathrm{~N})$ \\
\hline BS-D & $\begin{array}{l}\text { Double-ended cold-leg } \\
\text { LBLOCA }(2 \times 22 \mathrm{in})\end{array}$ & No & Yes & 2 & 2 & 4 & Yes & 8 & $1286(\mathrm{WC} / \mathrm{T})$ \\
\hline BS-E & $\begin{array}{l}\text { Spurious ADS-4 (4x11 } \\
\text { in.) }\end{array}$ & No & Yes & 1 & 1 & 4 & Yes & 2,6 & $845(\mathrm{WC} / \mathrm{T})$ \\
\hline \multicolumn{10}{|c|}{ Long-term Cooling } \\
\hline BS-F & $\begin{array}{c}\text { Double-ended DVI } \\
\text { line }(4 \text { in. })\end{array}$ & Yes & $1 / 1 \& 1 / 1$ & 1 & 0 & 3 & No & $1-5,7,9,10$ & $\begin{array}{l}\text { No core uncovery } \\
(\mathrm{N})\end{array}$ \\
\hline BS-G & $\begin{array}{l}\text { Double-ended DVI } \\
\text { line }(4 \text { in.) }\end{array}$ & No & $1 / 1 \& 1 / 1$ & 1 & 0 & 4 & No & $6,8,11-13$ & $\begin{array}{l}\text { No core uncovery } \\
(\mathrm{N})\end{array}$ \\
\hline
\end{tabular}




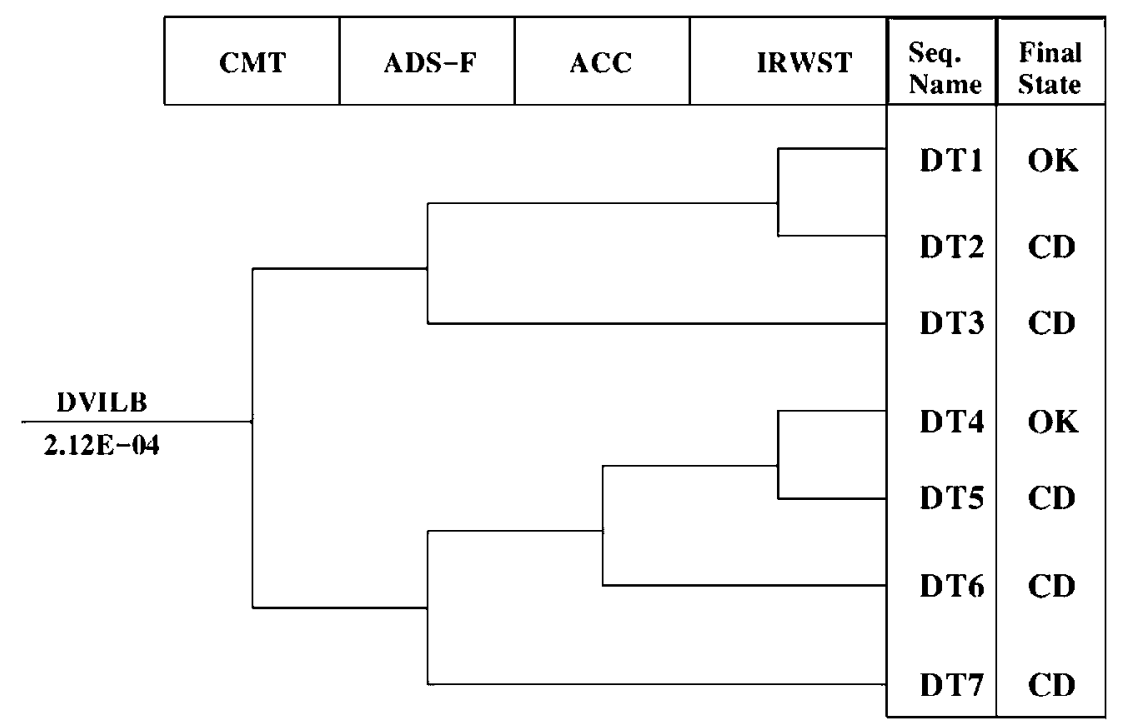

Fig. 4. DVILB event tree. Short term.

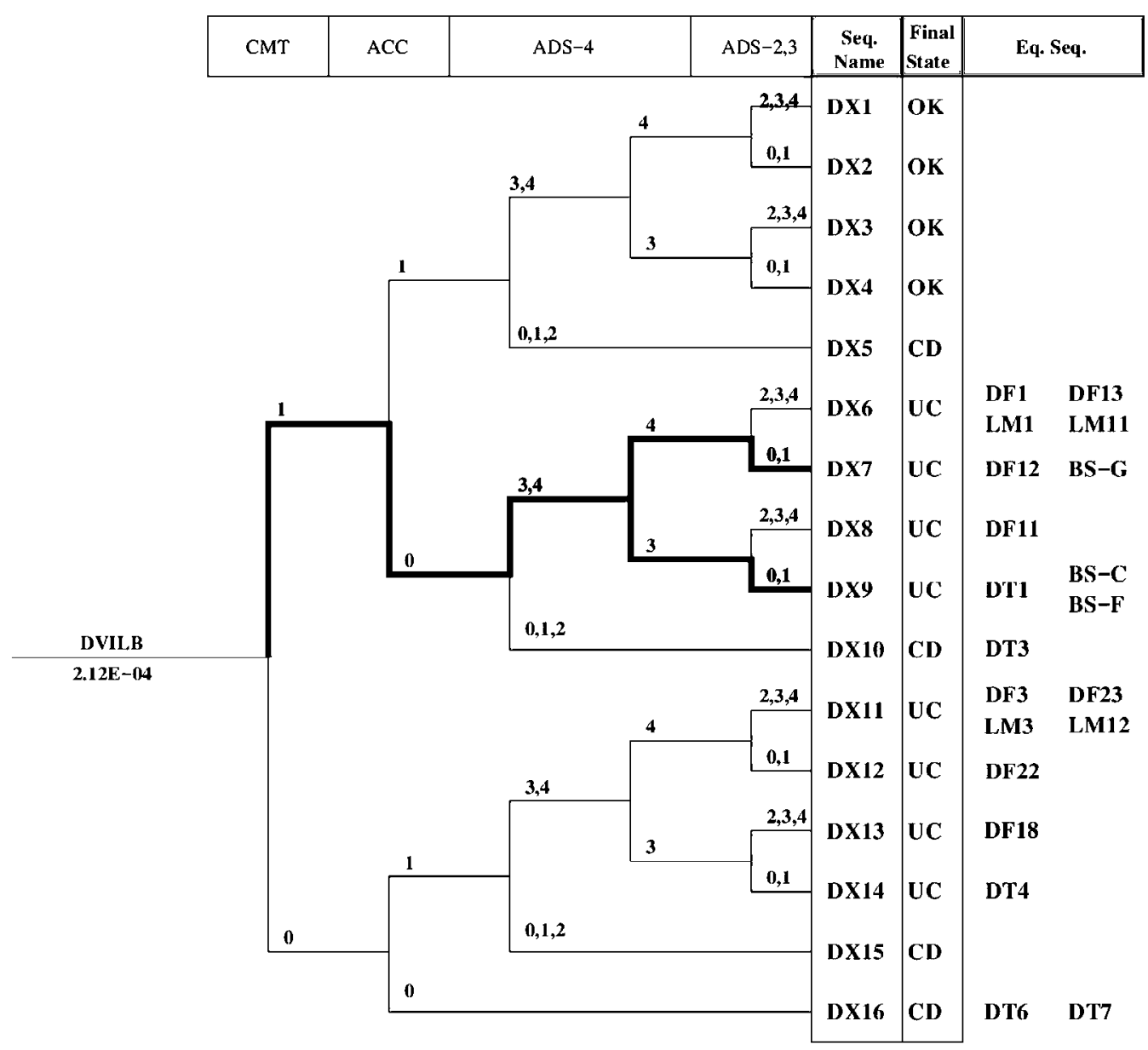

Fig. 5. DVILB EET. Short term.

- Sequences that were classified as low-margin risk-important sequences, Table 3 (LMi).

- Sequences that correspond to the low-margin bounding sequences, Table 4 (BS-k).
The corresponding DFi, LMi, and BS-k sequences associated to each EET are shown in Table 5. In addition, this table shows the frequency contribution to potential CDF in each EET. The comparison of potential CDF of these LMi sequences with respect to PRA Level 1 
Table 5

Important sequences associated to each EET for potential CDF.

\begin{tabular}{|c|c|c|c|c|}
\hline Initiating event & DFi & LMi & LMi CDF (contribution\%) & BS-k \\
\hline DVILB & DF1, DF3, DF11, DF12, DF13, DF18, DF22, DF23 & LM1, LM3, LM11, LM12 & $\begin{array}{l}1.20 \mathrm{E}-6 \\
(445.3 \%)\end{array}$ & $\begin{array}{l}\text { BS-C, BS-F, } \\
\text { BS-G }\end{array}$ \\
\hline SPADS & DF2, DF6, DF15 DF16 DF17 DF20 & LM2, LM6 & $\begin{array}{l}5.5 \mathrm{E}-7 \\
(227.9 \%)\end{array}$ & BS-E \\
\hline MBLOCA & DF4, DF7, DF10, DF24 & LM4, LM7, LM10, LM13 & $\begin{array}{l}3.22 \mathrm{E}-7 \\
(133.6 \%)\end{array}$ & BS-A \\
\hline CMTLB & DF5, DF9, DF14, DF25 & LM5, LM9 & $\begin{array}{c}1.40 \mathrm{E}-7 \\
(58.4 \%)\end{array}$ & BS-B \\
\hline LBLOCA & DF8 & LM8 & $\begin{array}{l}8.52 \mathrm{E}-9 \\
(3.5 \%)\end{array}$ & BS-D \\
\hline
\end{tabular}

$\mathrm{CDF}$, Table 3 and Table 5, indicates that many of these sequences could potentially increase the AP1000 CDF, therefore it is necessary to verify these sequences adequately.

\section{AP1000 LOCA sequences overview}

This section is intended to describe the behavior of the AP1000 reactor in case of LOCA sequences since all the low-margin sequences, that will be analysed thereafter, are different kinds of LOCA sequences (namely being BS-A, BS-B and BS-C MBLOCAs, and BS-D and BS-E LBLOCAs). In the following, a brief explanation about the phenomenology in case of MBLOCA and LBLOCA will be given.

As in a typical PWR, during a MBLOCA the RCS depressurizes rapidly. When the pressure drops to the reactor-trip setpoint (124 bar) the control rods are inserted, thus stopping the chain reaction. Subsequently, the RCS pressure decrease to the safetyinjection signal setpoint ( 117 bar) aligning the passive core cooling system, namely CMTs, ACCs, IRWST and operation of PRHR and automatically tripping the Reactor Coolant Pumps (RCPs). The main BE setpoints for LOCA sequences are collected in Table 6 . Four different phases can be identified in the AP1000 reactor during MBLOCA sequences, see references (Lafi and Reyes, 1999; Friend et al., 1997; Wright, 2007; Montero-Mayorga et al., 2015) for more details:

- Blowdown. The Blowdown phase corresponds to the initial pressure decreasing where the reactor trip and $\mathbf{S}$ signal are triggered.

- Natural circulation. Natural circulation phase is the period in which, after the trip of the RCPs, the RCS is cooled by natural circulation paths. When the valves of the CMTs and PRHR open, three additional natural circulation paths are established providing core cooling leading the RCS pressure to values below of SG pressure (Montero-Mayorga et al., 2015). This period ends

Table 6

Main setpoints for LOCA sequences (Westinghouse Electric Company, 2008) (BE values).

\begin{tabular}{ll}
\hline System & Setpoint \\
\hline Reactor SCRAM & 124 bar \\
S signal & 117 bar \\
CMT injection & S signal +2 second delay \\
SG main FW valves start to close & S signal +5 second delay \\
RCP trip & S signal +6 second delay \\
PRHR alignment & S signal \\
ACC injection & 49 bar \\
ADS-1 & CMT low level (67.5\%) \\
ADS-2 & 48 second after ADS-1 \\
ADS-3 & 120 second after ADS-2 \\
ADS-4 & 128 second after ADS-3 \& \\
& CMT low-low (20\%) \\
IRWST squib valves open & ADS-4 actuation \\
\hline
\end{tabular}

with ADS-1 actuation. Unlike typical PWRs the steam generators are not as important during MBLOCAs in AP1000 since the PRHR is activated very early in the accident and the IRWST serves as primary heat sink (Montero-Mayorga et al., 2015). The CMTs remain in recirculation mode and steam starts to replace water at the top of the tanks until the level in at least one CMT reaches about the 67.5\% level and the ADS actuation signal is activated.

- ADS blowdown. Once 1 out of 2 CMTs level is about $67.5 \%$ the ADS-1 valves open automatically, at this time the ADS blowdown phase starts. After a short delay, ADS-2/3 actuate. When at least one CMT reaches about $20 \%$ level, the ADS- 4 valves open. Thanks to the pressure reduction through the ADS valves as well as through the break, the setpoint for ACC actuation is reached ( 49 bar). This fact makes possible that the borated water contained in the ACCs drains into the RCS. ACCs injection stops partial or totally the flow from the CMTs due to the larger ACCs flow through the DVIs.

- IRWST injection. The short-term cooling ends with the IRWST injection phase. The actuation of the ADS-4 helps to reduce the RCS pressure near to containment pressure allowing the injection of borated water from the IRWST by gravity. After that, long-term cooling for MBLOCA is established.

In case of LBLOCA or spurious ADS-4 actuation the RCS depressurizes very fast to atmospheric conditions and the ADS-1/2/3 are not necessary to allow ACCs injection. This kind of scenario presents the following phases (Queral et al., 2015):

- Blowdown. Two sub-phases can be differentiated during this period, early and late blowdown, (Lime et al., 1994). During early blowdown ( 0.0 to $15 \mathrm{~s}$ ) a fast depressurization of the RCS is produced. The core becomes almost completely voided in about $2 \mathrm{~s}$.

The rapid loss of coolant causes fuel cladding temperatures to increase rapidly, producing a first maximum. Subsequently, during late blowdown (15-35s) the ACC setpoint is reached and start to discharge. During a few seconds (typically $10 \mathrm{~s}$ ) the flow injected by the ACCs is bypassed towards the broken loop due to the lower pressure in the break location.

- Refill. After further depressurization, the steam flow has dropped to a sufficiently low value that it cannot longer restrict the ingress of $A C C$ water through the downcomer. The water injected by the ACCs reaches and refills the lower plenum during the next $15 \mathrm{~s}$. At this time the fuel cladding temperatures continues rising.

- Reflood. Once the lower plenum has been refilled, core reflood and quenching begins. The rewet produces a larger amount of steam which is able to cool the upper part of the core. Thus, the fuel temperatures reach a maximum and then start to decrease. The end of reflood occurs 200 s later. 
The sequences which are analysed in this paper present unavailability of several of the systems commented above, therefore the low-margin bounding sequences will be different in some points of the sequence evolution compared with a standard LOCA.

\section{AP1000 TRACE model nodalization and hypotheses}

The AP1000 TRACE model used through the analysis consists of all the main components such as Vessel, Steam Generators, Pressurizer, RCPs and connecting pipes as well as the passive safety systems, CMTs, ACCs, ADS and PRHR. No active systems are implemented in this model. The total number of thermal hydraulic components included in the TRACE model is 368, being 86 PIPEs, 191 HTSTRs, 3 POWERs, 44 VALVEs, 4 PUMPs, 24 BREAKs, 10 TEEs, 3 FILLs and 3 VESSELs, see Fig. 6.

The reactor vessel is modeled in three-dimensional cylindrical coordinates, with four radial rings and 17 axial levels. Two TRACE vessels are used to model the vessel, the first vessel component models the lower plenum, core and upper plenum. The second vessel component is used to model the downcomer with two radial rings, eight azimuthal sectors and 13 axial levels. The ADS is modeled such as the actual design, with the first 3 stages connected from the top of the pressurizer to the IRWST and the fourth connected to both hot legs. Safety relief valves and pilot operated relief valves are implemented in steam lines as well. The IRWST is modeled with a Cartesian vessel of 4 axial levels. The model also implements several controls such as PZR level and pressure, SG level and safeguards signals (e. g. reactor trip, safety injection and RCP trip).

In addition, 119 TRIPS, 377 CONTROL BLOCKS and 447 SIGNAL VARIABLES complete the model. In Table 7 , the steady-state values achieved with TRACE are compared with the steady-state values of AP1000 plant design (Westinghouse Electric Company, 2008). In addition main conservative hypotheses considered in the model are listed in Table 8.

This model has been previously applied in different LOCA analysis including the assessment of deterministic safety analysis for SBLOCA, MBLOCA and also LBLOCA sequences, see (MonteroMayorga et al., 2015, 2014; Queral et al., 2015; Queral and Montero-Mayorga, 2016).

\section{Analyses of AP1000 low-margin bounding sequences based on best-estimate calculations}

As described in the previous section, once the low-margin bounding sequences (BS-k) have been identified, DSA methodolo-
Table 7

Steady-state values for AP1000 TRACE-model.

\begin{tabular}{lll}
\hline Variable & TRACE BE & Plant design \\
\hline Thermal power (MWt) & 3415.0 & 3415.0 \\
PZR pressure (bar) & 155.8 & 155.1 \\
Vessel inlet temperature $(\mathrm{K})$ & 552.4 & 553.7 \\
Vessel outlet temperature $(\mathrm{K})$ & 595.9 & 594.1 \\
Vessel Flow mass flow rate $(\mathrm{kg} / \mathrm{s})$ & 14373.6 & 15100.0 \\
SG pressure (bar) & 55.4 & 57.6 \\
Feed Water temperature $(\mathrm{K})$ & 499.72 & 499.85 \\
Feed Water mass flow rate $(\mathrm{kg} / \mathrm{s})$ & 1912.0 & 1885.0 \\
\hline
\end{tabular}

Table 8

Main conservative hypotheses implemented in the AP1000 TRACE model.

\begin{tabular}{ll}
\hline Nominal core power & $102 \%$ \\
\hline Decay Heat & ANS-1971 +20\% \\
ACC pressure set-point & 49 bar \\
IRWST, ACC and CMT temperature & $321.8 \mathrm{~K}$ \\
Main feed water valves closing & Between 2 and 7 second after S signal \\
$\quad$ time & 6 second after reactor trip \\
SG isolation & 85.14 bar \\
SG Safety valves setpoint & Friction factors increased in discharge \\
Safety injection & lines \\
&
\end{tabular}

gies are used to evaluate these sequences in order to demonstrate that $\mathrm{T} / \mathrm{H}$ uncertainties are bounded. As shown in Table 4, five shortterm bounding sequences and two long-term bounding sequences were determined (Westinghouse Electric Company, 2003a). The results obtained by WEC (last column of Table 4) shows that only four low margin bounding sequences present core uncovery but they do not exceed Peak Cladding Temperature (PCT) acceptance criterion in any case (PCT $<1477 \mathrm{~K})$.

The UPM group has verified all the short-term BS-k sequences with the best-estimate TRACE code applying a SSG-2 option 2 methodology in order to verify the results obtained by WEC which applied SSG-2 option 1 and option 3 methodology with NOTRUMP/ LOCTA and WCOBRA/TRAC codes respectively. As mentioned previously, the considered AP1000 TRACE model implements some conservatisms from DCD chapter 15 , Table 8 . The bounding sequences that are simulated and analysed are:

- BS-A. Hot leg break (3 in.)

- BS-B. Double-ended guillotine break (DEGB) in CMT balance line (6.8 in.)

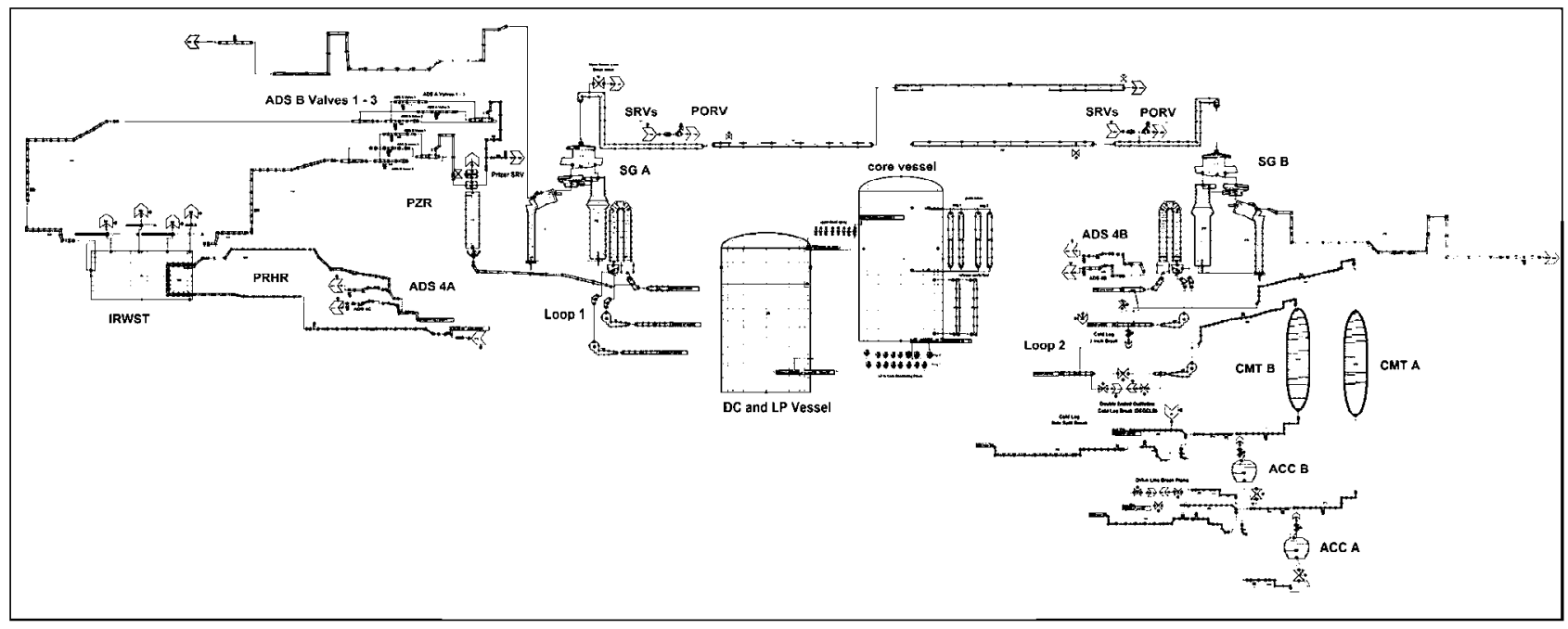

Fig. 6. AP1000 TRACE model in SNAP nodalization. 
- BS-C. DEGB in DVI line $(2 \times 4$ in. $)$

- BS-D. DEGB in cold leg $(2 \times 22$ in. $)$

- BS-E. Spurious ADS-4 actuation ( $4 \times 11$ in.)

All of these BS-k sequences have core uncovery according to MAAP simulations, and all of them (except of BS-E) require ADS4 actuation, IRWST injection and recirculation. On the other hand, all the LMi sequences include ADS-2/3 actuation but none of the $\mathrm{BS}-\mathrm{k}$ sequences include this ADS actuation.

As it is stated in the PRA analysis, in the medium LOCA sequences where both CMTs fail to inject (BS-A, BS-B), automatic actuation of PRHR is required to provide adequate time for the operators to actuate the ADS-4 manually (Westinghouse Electric Company, 2003a). All the BS-k sequences with manual ADS-4 actuation (BS-A, BS-B) perform this human action at 20 min after the $S$ signal which corresponds to its available time (Westinghouse Electric Company, 2003b).

It must be remarked that NOTRUMP simulations (BS-A, BS-B and BS-C) include a conservative RCP trip delay ( $\mathrm{S}$ signal $+16 \mathrm{~s}$, see (Westinghouse Electric Company, 2003a) instead of the BE value included in TRACE model ( $\mathrm{S}$ signal $+6 \mathrm{~s}$, see Westinghouse Electric Company, 2008 chapter 15).

\subsection{Hot leg break. Low-margin bounding sequence A (BS-A)}

BS-A sequence, presents the following safety systems availability for the accident mitigation: no CMTs, no ADS-1/2/3, credit for 4 out of 4 ADS- 4 valves, 1 out of 2 ACCs, 1 out of 2 IRWST injection lines and PRHR actuation, Fig. 7.

The break size of this sequence ( 3 in.) was selected because the ACC injection occurs at the time the operators actuate the ADS-4 manually (Westinghouse Electric Company, 2003a). Since in this sequence the CMTs fail, the RCS pressure remains above ACC pressure injection until the operator actuate the ADS. That results in a period of $20 \mathrm{~min}$ in which no water is refilling the RCS. Thus, core uncovery can be reached until ACC injection.

The TRACE results are plotted comparing with those obtained with NOTRUMP by WEC (Westinghouse Electric Company, 2003a) and the chronology of the sequence is presented in Table 9.
The results obtained with TRACE show a good agreement with the NOTRUMP ones. As it is depicted in Fig. 8, the pressure decreases until 75 bar where stabilizes for a period of about $500 \mathrm{~s}$. Then, the pressure decreases linearly down to the manual actuation of ADS-4 is performed ( $1200 \mathrm{~s}$ after S signal) (Westinghouse Electric Company, 2003a). This ADS-4 actuation allows the ACC discharge, Fig. 9. Subsequently and due to reaching nearly atmospheric conditions, the IRWST starts to discharge water into the RCS, Fig. 9. It is appreciable that the TRACE IRWST mass flow is higher than the NOTRUMP one, probably due to a more conservative model in NOTRUMP (e.g. larger friction values). Previous SBLOCA (2 in.) analysis showed a similar IRWST mass flow discrepancy between both codes, see (Montero-Mayorga et al., 2015). However, in other LOCA cases with higher break sizes a similar IRWST mass flow was observed for TRACE and NOTRUMP simulations, see (MonteroMayorga et al., 2015).

In both simulations, the minimum predicted RCS inventory is quite similar, Fig. 10 . However, after $1500 \mathrm{~s}$ the RCS inventory presents some differences due to the greater makeup from the IRWST in TRACE. It must be noted, that in the NOTRUMP case a small core uncovery can be appreciated near to the ADS actuation $(P C T=670 \mathrm{~K}$ ), see Westinghouse Electric Company, 2003a and Fig. 11. However, such behavior is not predicted with TRACE, probably due to the greater RCS inventory until the ADS is manually actuated, Figs. 11 and 12.

6.2. DEGB in CMT balance line. Low-margin bounding sequence B (BSB)

BS-B sequence presents the following safety systems availability for the accident mitigation: no CMTs, no ADS- $1 / 2 / 3$, credit for 4 out of 4 ADS- 4 valves, 2 out of 2 ACCs, 1 out of 2 IRWST injection lines and PRHR actuation, Fig. 13.

The TRACE results are plotted comparing with those obtained with NOTRUMP by WEC (Westinghouse Electric Company, 2003a) and the chronology of the sequence is presented in Table 10. The results obtained with TRACE shows a good agreement with the NOTRUMP ones.

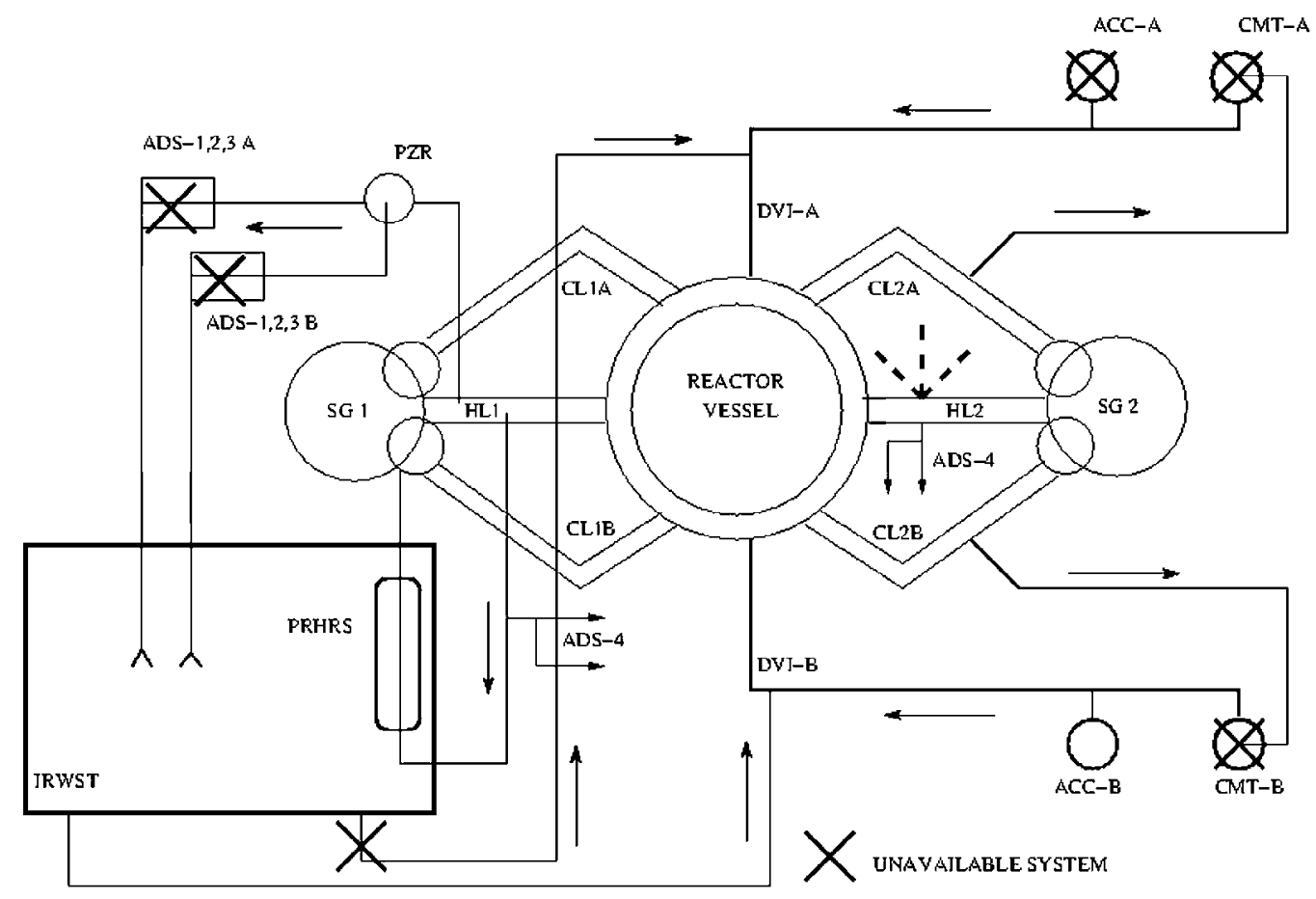

Fig. 7. Hot Leg LOCA (BS-A). Availability of safety systems. 
Table 9

Hot Leg LOCA (BS-A). Sequence chronology

\begin{tabular}{lll}
\hline Event & TRACE $(\mathrm{s})$ & NOTRUMP $(\mathrm{s})$ \\
\hline Break occurs & 0.0 & 0.0 \\
Reactor trip & 27.0 & 39.0 \\
S signal & 35.0 & 47.0 \\
RCP trip & 41.0 & 63.0 \\
ACC injection starts & 1200.0 & 1200.0 \\
Manual ADS-4 actuation & 1235.0 & 1247.0 \\
IRWST injection & 1283.0 & 1500.0 \\
\hline
\end{tabular}

The results of both codes show that the CMT line break (6.8 in.) results in a rapid RCS depressurization and ACCs injection, Figs. 14 and 15 . Once the ACCs are empty there is no more injection capability until the IRWST injects, and then it is necessary to actuate manually the ADS-4 in order to depressurize the RCS until atmospheric conditions before the ACCs are empty (about $1200 \mathrm{~s}$ after S signal) (Westinghouse Electric Company, 2003a). This human action allows maintaining the core covered and therefore high PCT values are not reached, Figs. 16-18.

\subsection{DEGB in DVI line. Low-margin bounding sequence $C(B S-C)$}

BS-C sequence presents the following safety systems availability: 1 out of 2 CMT (intact loop), 0 out of 2 ACC, ADS-1/2/3 failed, credit for automatic actuation of 3 out of 4 ADS- 4 valves and the IRWST corresponding to the intact line, see Fig. 19. The size of the DVI line is $6.8 \mathrm{in}$. but the inlet nozzle (vessel side) presents a 4-inch flow restrictor which limits the effective break size and hence the maximum flow that can be discharged through the break. It must be remarked that this bounding sequence is quite important since it bounds the low-margin sequence with largest

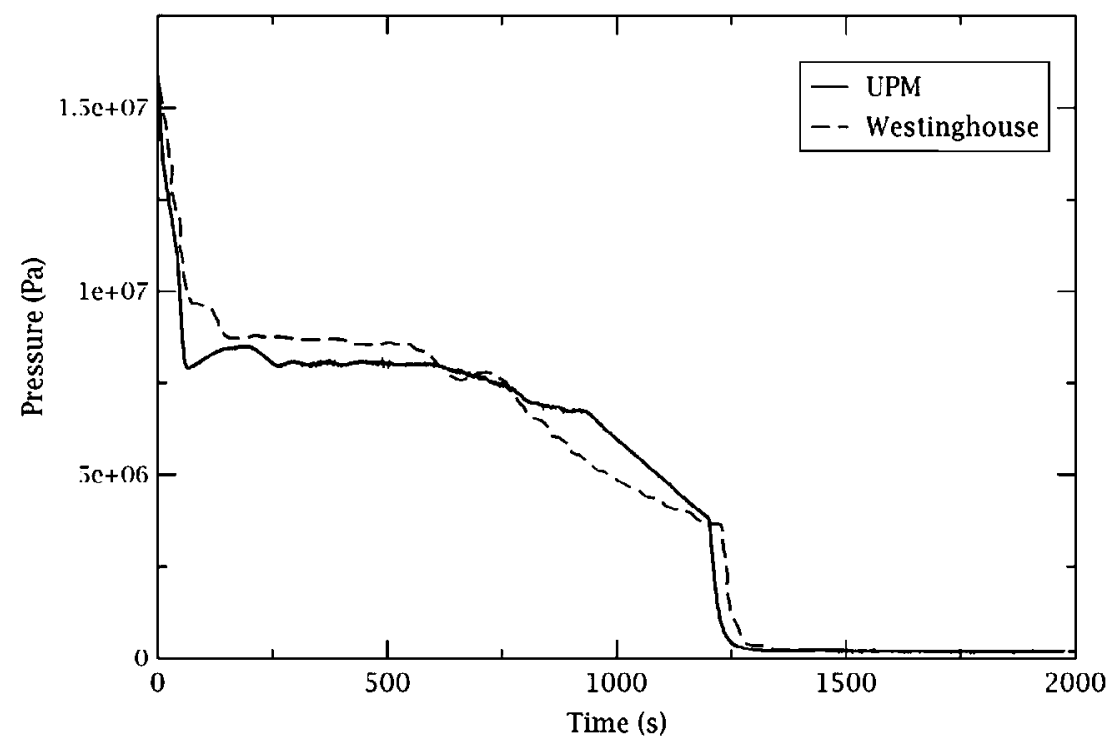

Fig. 8. RCS pressure (Hot Leg LOCA, BS-A).

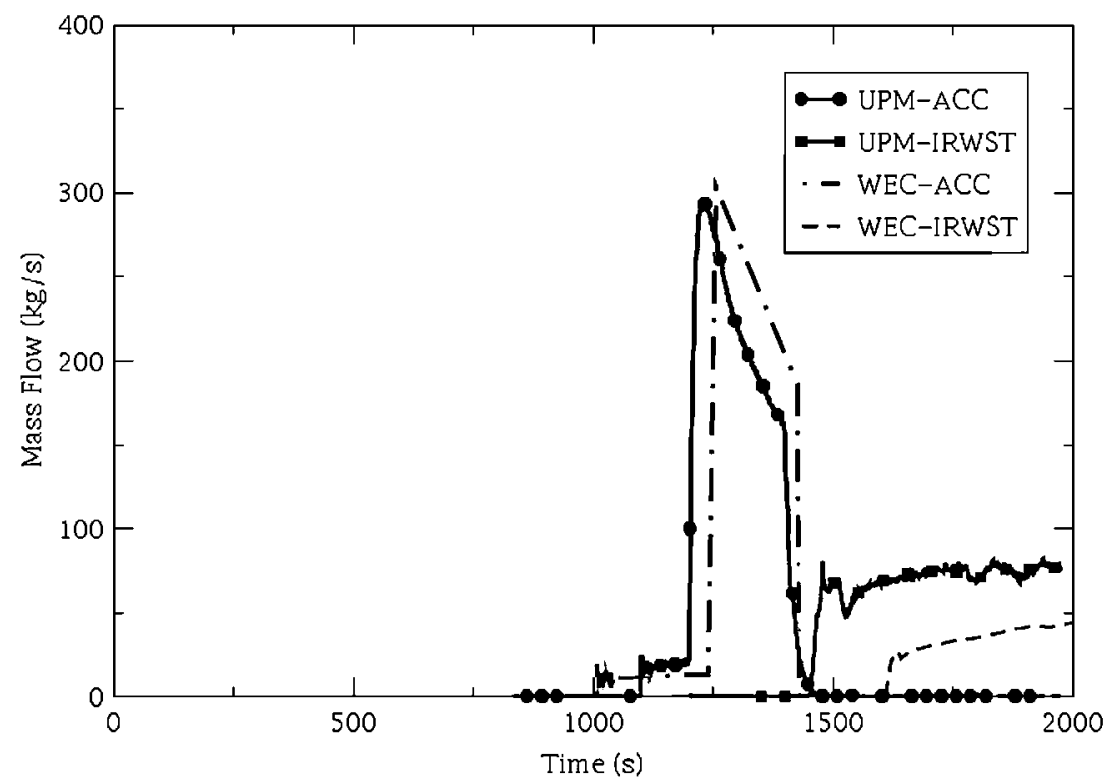

Fig. 9. ACC and IRWST injection (Hot Leg LOCA, BS-A). 


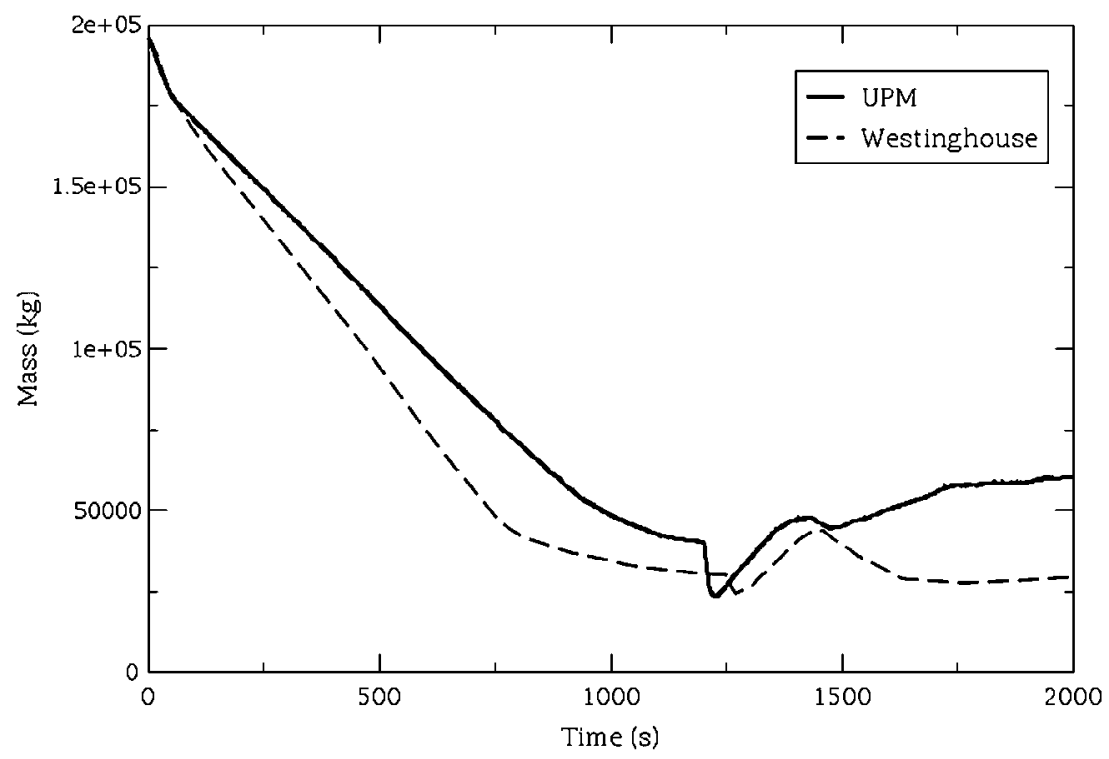

Fig. 10. RCS Inventory (Hot Leg LOCA, BS-A).
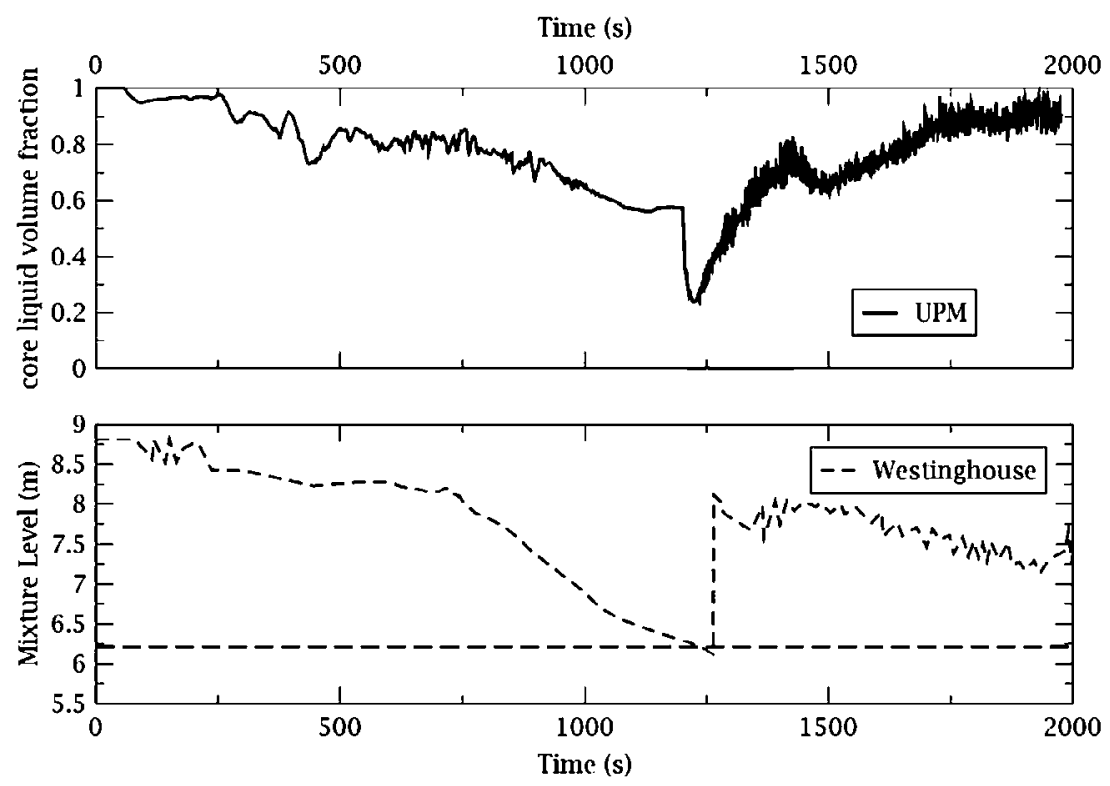

Fig. 11. Core liquid volume (Hot Leg LOCA, BS-A).

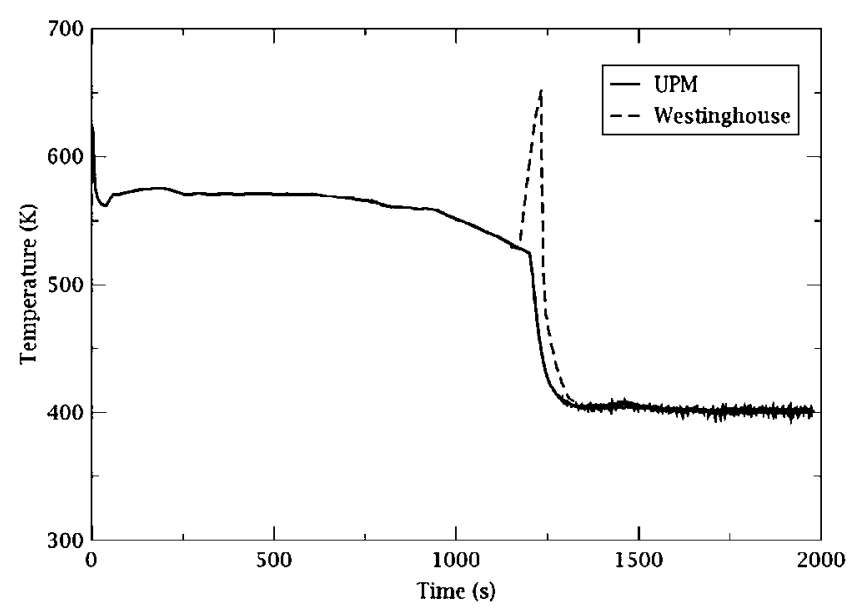

Fig. 12. PCT (Hot Leg LOCA, BS-A). contribution to potential CDF and LRF (LM1) but also LM7, LM9 and LM11 sequences, see Table 4.

TRACE results are plotted comparing with those obtained by WEC with NOTRUMP code (Westinghouse Electric Company, 2003a) and the chronology of the sequence is presented in Table 11. As it is depicted in Fig. 20 and Fig. 22, the pressure and RCS inventory transient presents a similar trend in both cases and the automatic actuation of ADS-4 is achieved close to 1550 s for WEC and UPM simulations.

In this sequence the available CMT is the only way to cool the core until the ADS-4 actuation allows the injection of the IRWST. Although the CMT flow predicted by TRACE is slightly greater, Fig. 21, the trend is quite similar for both codes. The time in which the ADS- 4 actuates (CMT level $=20 \%$ ) is appreciable in both cases since the CMT mass flow rate is increased, Fig. 21 , and the RCS pressure drops simultaneously, Fig. 20.

Later, when the IRWST injection is achieved, the RCS is again pressurized above the IRWST injection pressure, which produces 


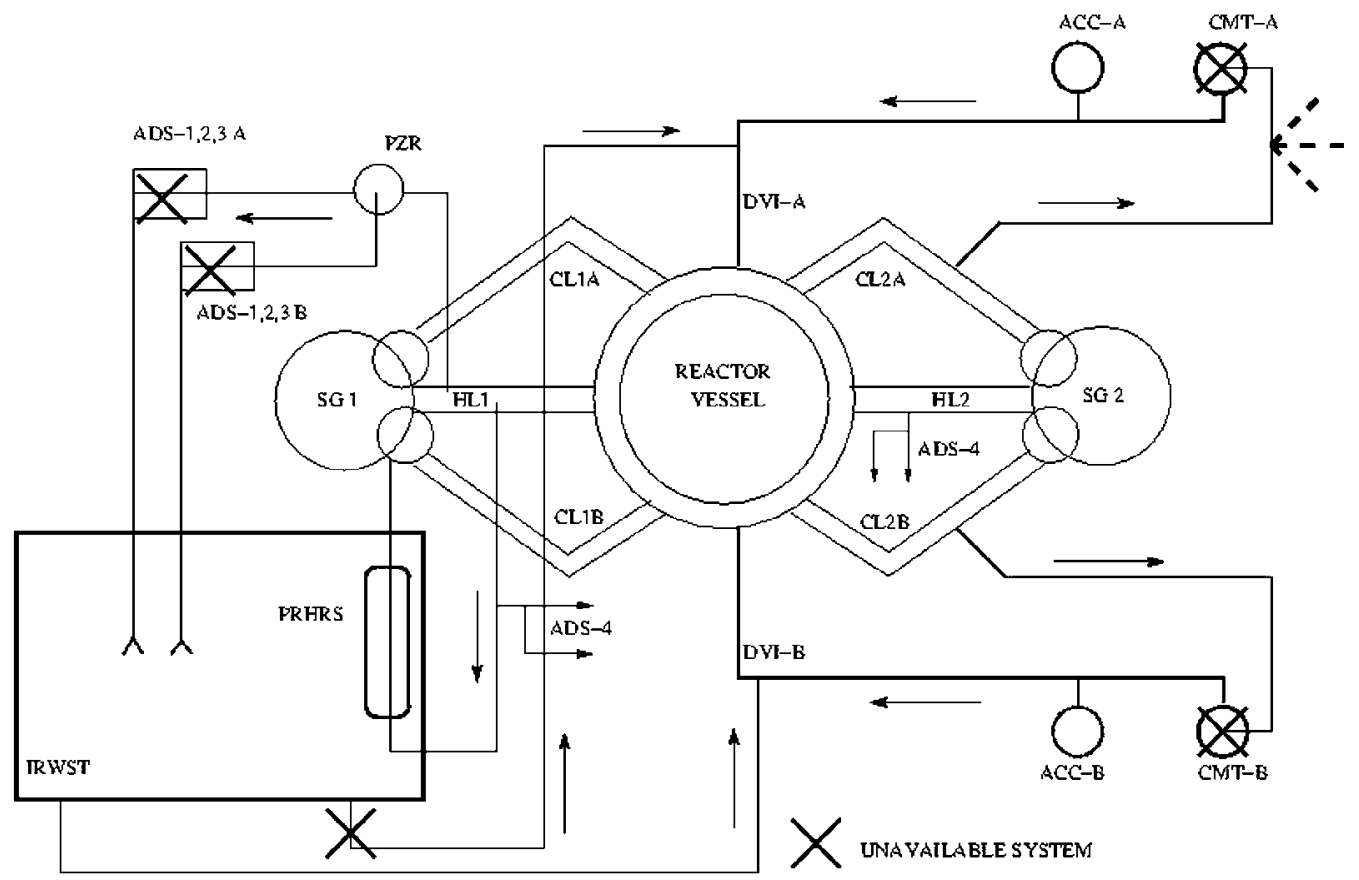

Fig. 13. DEGB in CMT balance line (BS-B). Availability of safety systems.

Table 10

DEGB in CMT balance line (BS-B). Sequence chronology.

\begin{tabular}{lll}
\hline Event & TRACE $(\mathrm{s})$ & NOTRUMP $(\mathrm{s})$ \\
\hline Break occurs & 0.0 & 0.0 \\
Reactor trip & 10.0 & 10.7 \\
S signal & 12.0 & 16.7 \\
RCP trip & 18.0 & 32.7 \\
ACCs injection starts & 233.0 & 290.0 \\
Manual ADS-4 actuation & 1212.0 & 1217.0 \\
IRWST injection & 1388.0 & 1450.0 \\
\hline
\end{tabular}

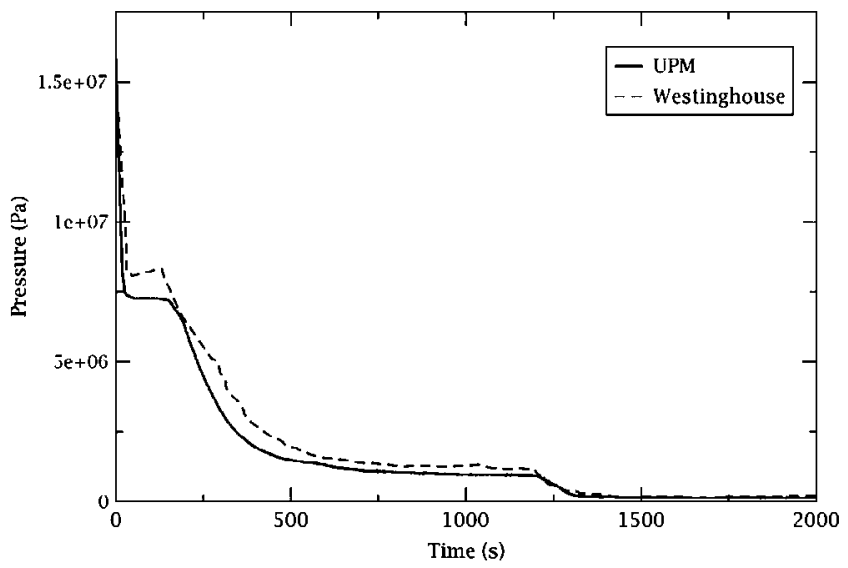

Fig. 14. RCS pressure (DEGB in CMT balance line, BS-B).

a short interruption in the IRWST mass flow rate, Fig. 21. The minimum core level is reached at about 1900 s producing a fast PCT rise. When the water from the IRWST flows into the system, the core level is recovered and the temperatures decrease. It is appreciable that the PCT value obtained with NOTRUMP (1127 K), Table 4 , is higher than the obtained with TRACE code $(871 \mathrm{~K})$, Fig. 23 and Fig. 24. This is an expected result since NOTRUMP analysis includes more conservative models and assumptions than TRACE.

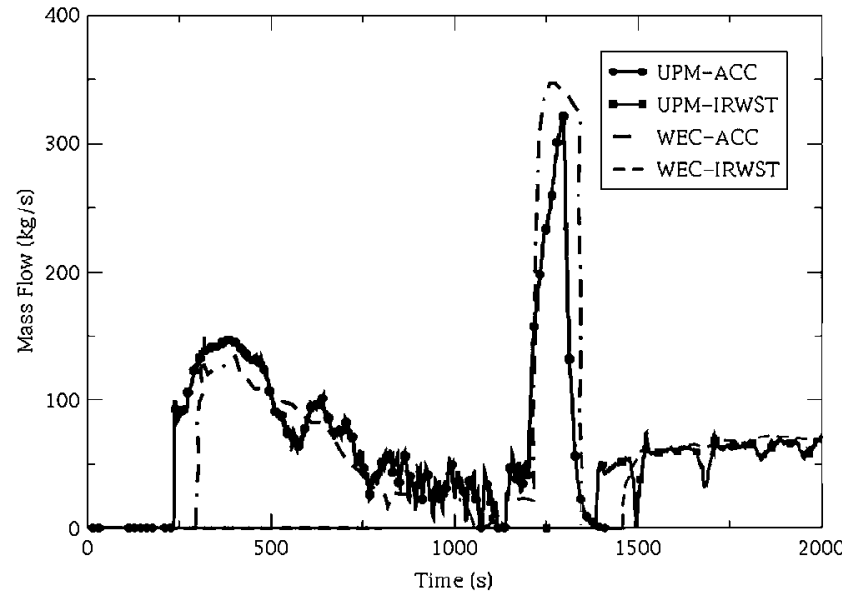

Fig. 15. ACCs and IRWST injection (DEGB in CMT balance line, BS-B).

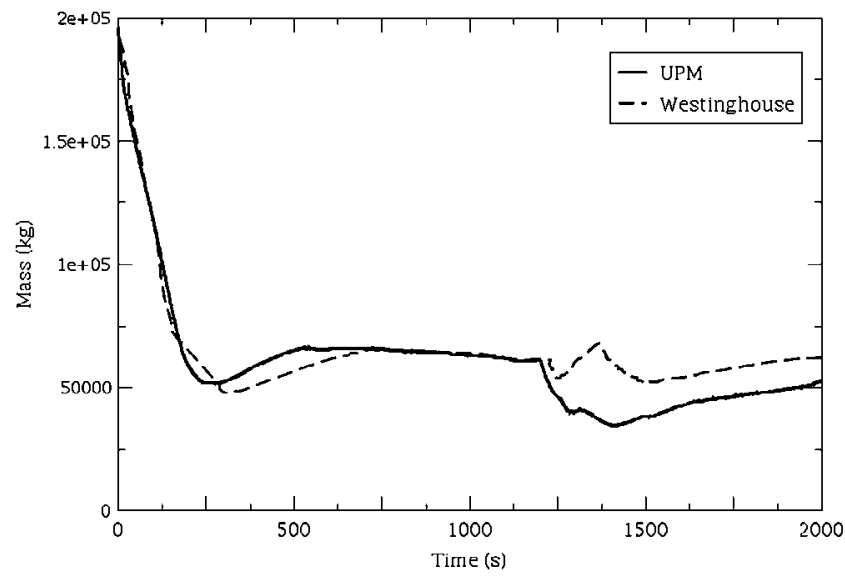

Fig. 16. RCS Inventory (DEGB in CMT balance line, BS-B). 


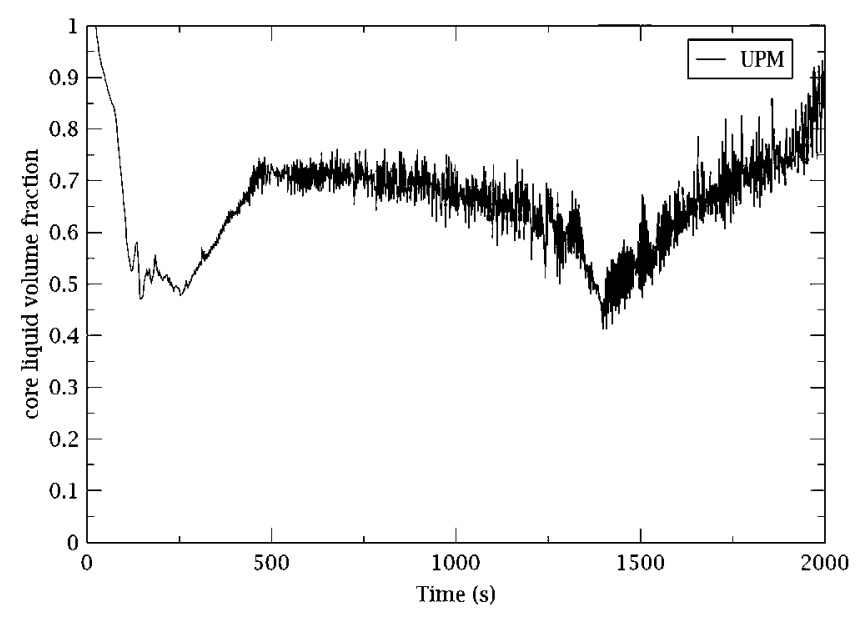

Fig. 17. Core liquid volume fraction (DEGB in CMT balance line, BS-B).

\subsubsection{Sensitivity to CMT availability}

In this section a modified BS-C sequence which considers 2 out of 2 CMTs instead of 1 out of 2 CMTs is analysed. The previous analysis of BS-C assumes the hypothesis that the CMT connected to the broken DVI is not available. However, it must be reminded that the discharge of the CMT demands the actuation of ADS- 1 at $67 \%$ CMT level and subsequently the ADS-4 at 20\% CMT level. Therefore, if the CMT located in the broken loop is available, it could discharge its entire inventory in a short time, demanding the automatic actuation of ADS-4 and producing a large break in the hot legs (ADS-4 valves) along with the break of one of the DVI lines. Moreover such sequence is more likely than a sequence in which one of the CMTs is not available.

Although this modified sequence is not considered as lowmargin bounding sequence, the UPM group decided to perform this sensitivity analysis in order to check that no worse consequences would be expected in this case. As commented beforehand, the

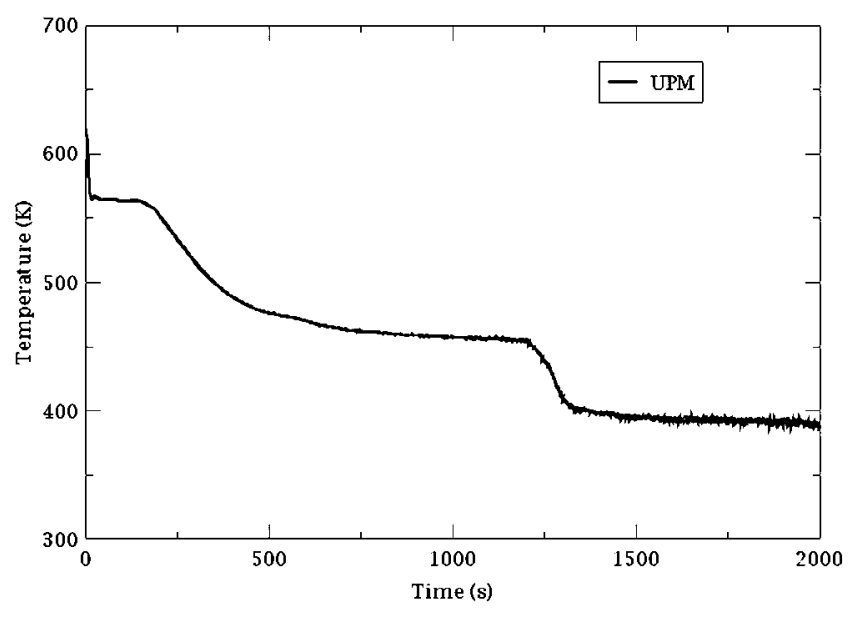

Fig. 18. PCT (DEGB in CMT balance line, BS-B).

Table 11

DVILB (BS-C). Sequence chronology.

\begin{tabular}{lll}
\hline Event & TRACE $(\mathrm{s})$ & NOTRUMP $(\mathrm{s})$ \\
\hline Break occurs & 0.0 & 0.0 \\
Reactor trip & 24.3 & 13.4 \\
S signal & 27.2 & 20.0 \\
RCP trip & 33.2 & 36.0 \\
CMT injection starts & 39.2 & $\mathrm{~N} / \mathrm{A}$ \\
Auto ADS-4 & 1355.0 & 1380.0 \\
IRWST injection & 1870.3 & 1960.0 \\
Maximum PCT & 1995.1 & $\approx 2200.0$ \\
\hline
\end{tabular}

CMT in the broken line discharges very quickly, Fig. 25, demanding ADS- 4 actuation before in the case where the CMT is available, Fig. 26. Thus, a faster depressurization transient is appreciated, Fig. 27.

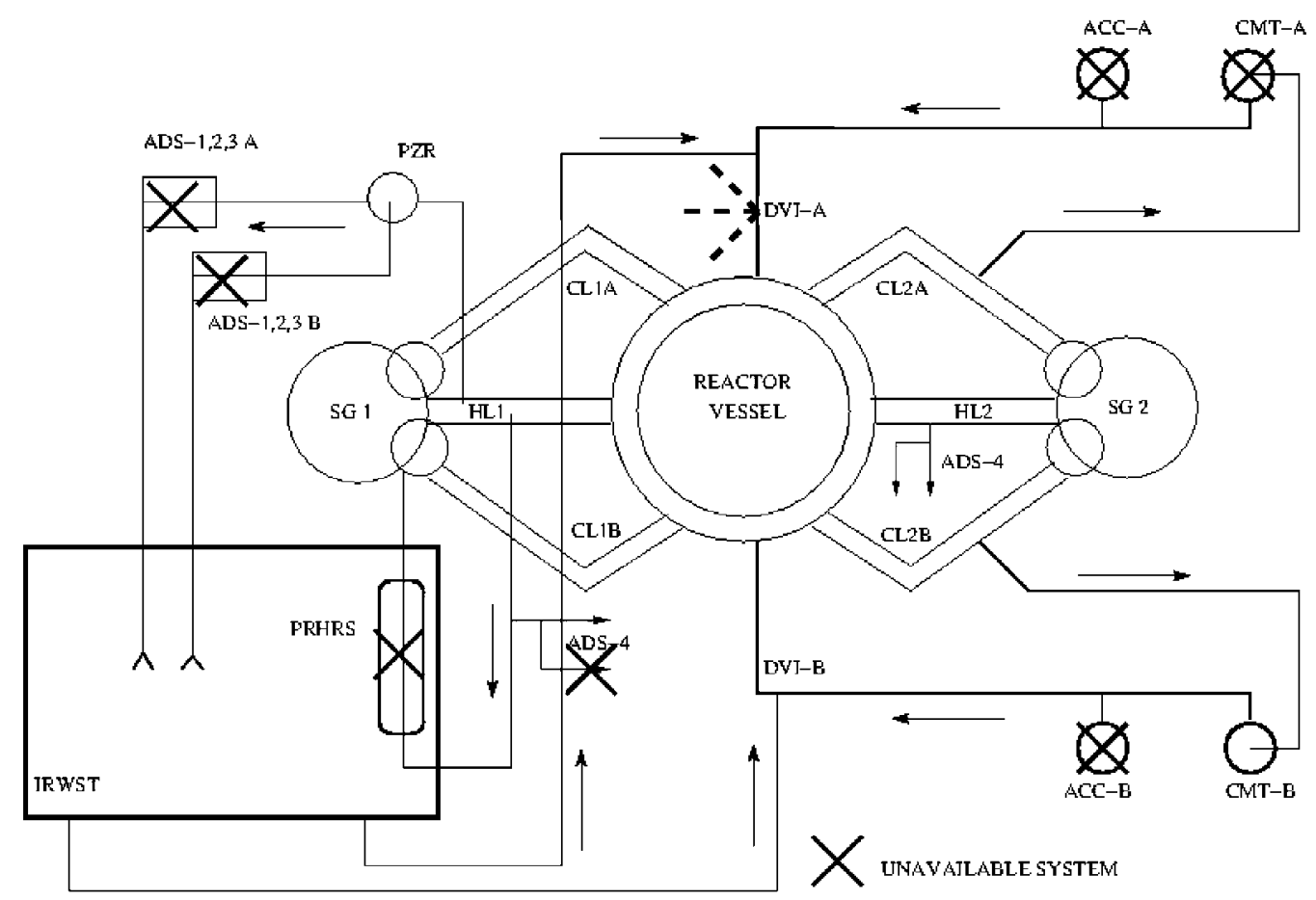

Fig. 19. DVILB (BS-C). Availability of safety systems. 


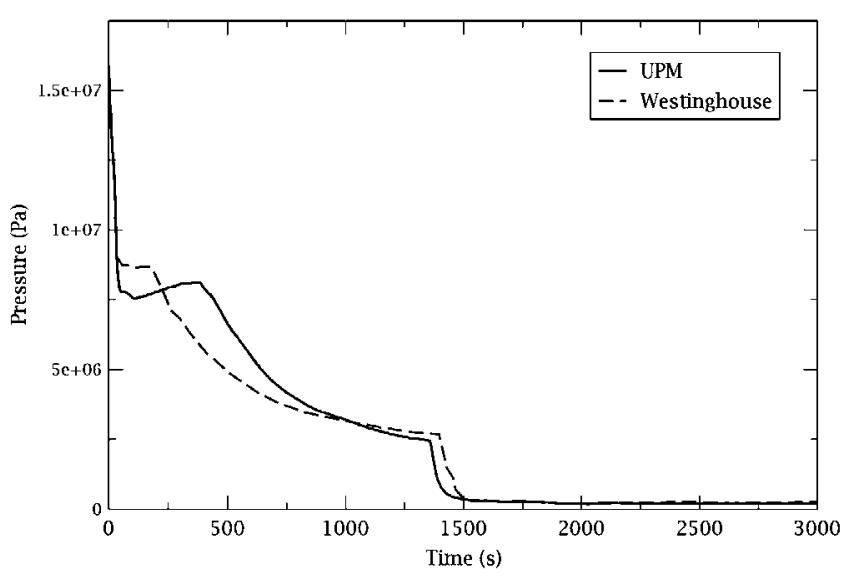

Fig. 20. Pressure transient (DVILB, BS-C).

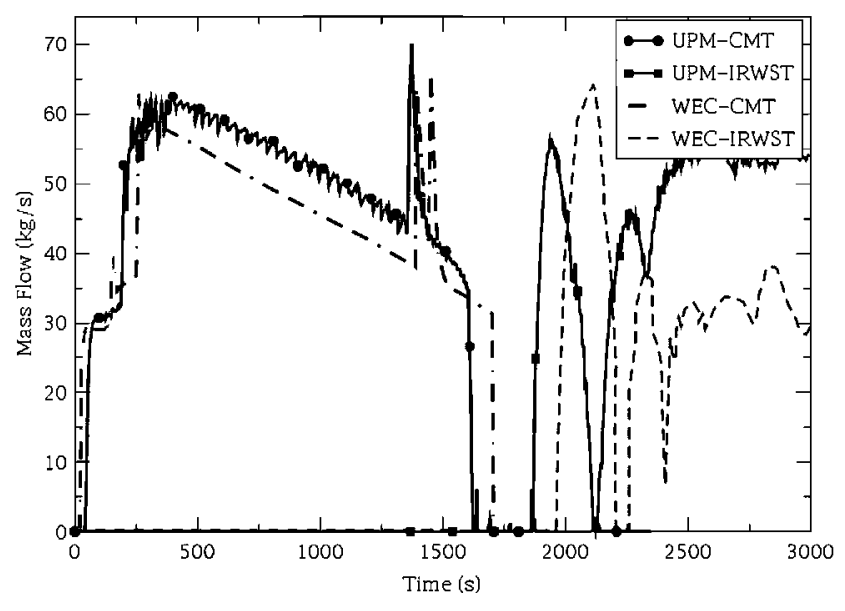

Fig. 21. CMT and IRWST injection mass flow rate (DVILB, BS-C).

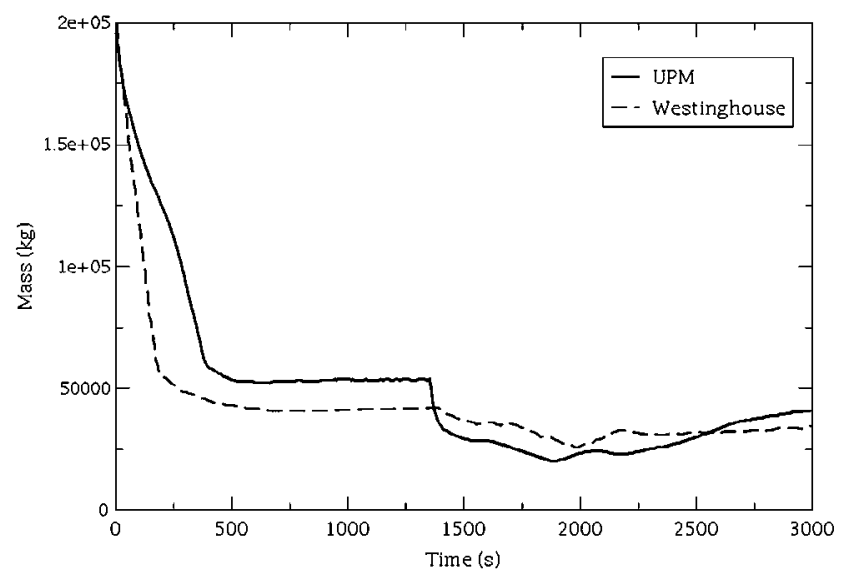

Fig. 22. RCS Inventory (DVILB, BS-C).

However, contrary to the behavior that could be expected due to the faster depressurization, the IRWST injection does not inject earlier. Such fact is due to the injection provided by the CMT. This system is driven by the steam produced in the cold legs which pushes the water contained in CMTs and until this system is not empty, the IRWST cannot inject properly in both cases.

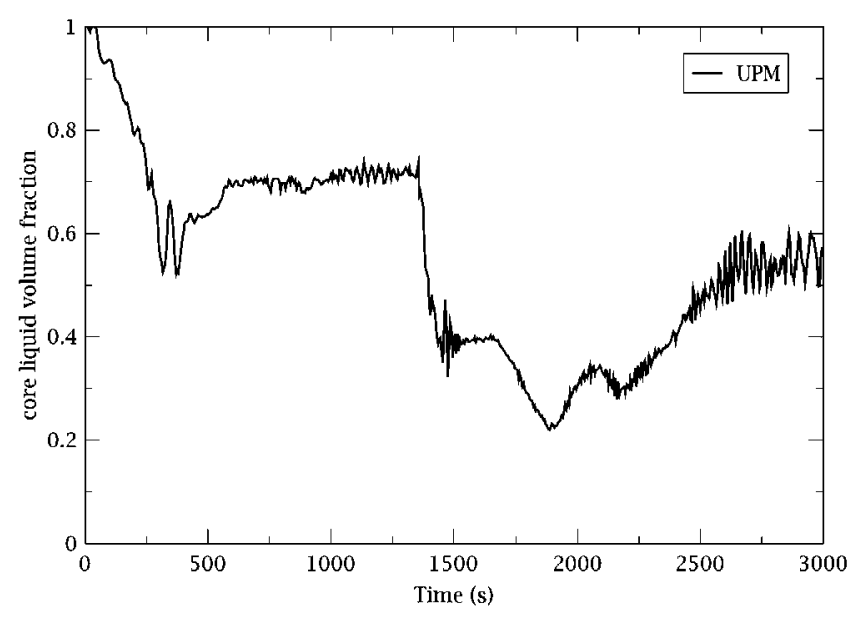

Fig. 23. Core liquid volume fraction (DVILB, BS-C).

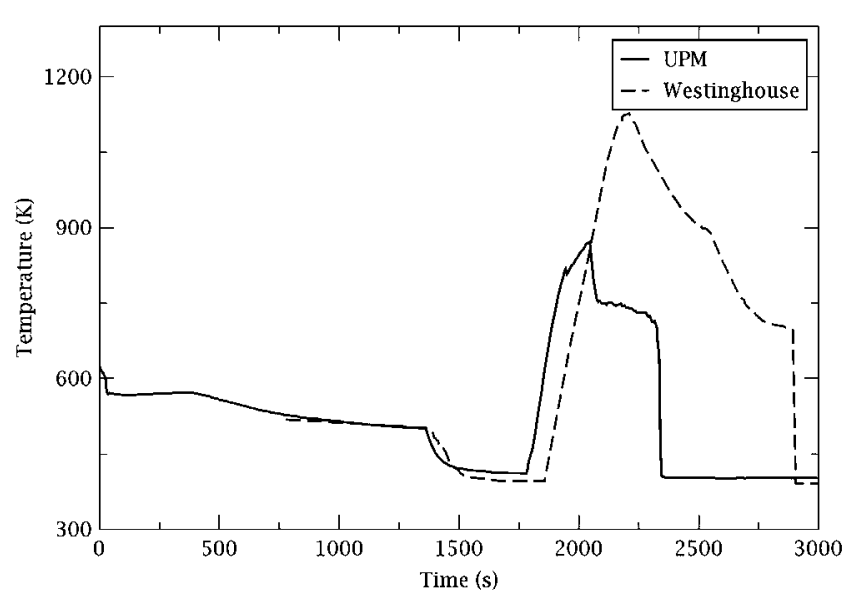

Fig. 24. PCT (DVILB, BS-C).

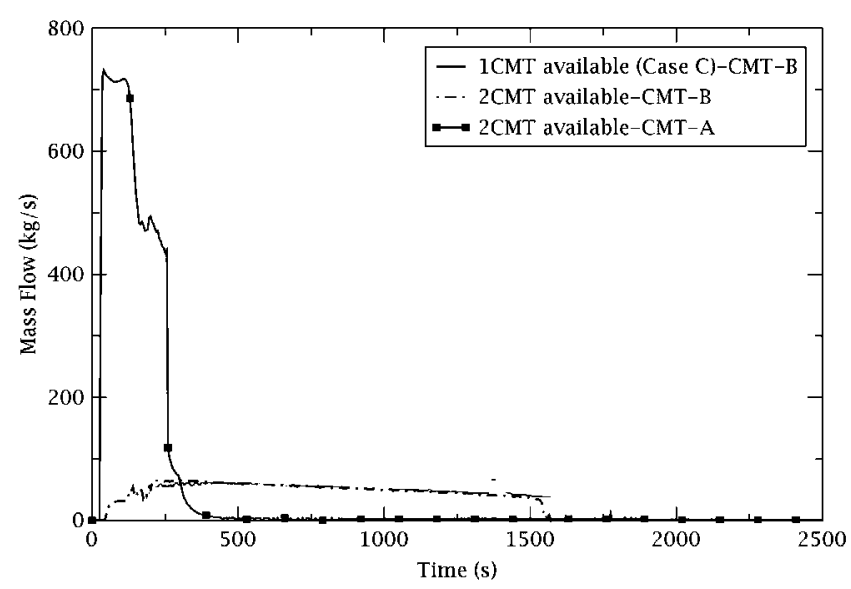

Fig. 25. CMTs mass flow (BS-C). Sensitivity to CMT availability.

Nevertheless, an appreciable difference between both cases is observed. When the IRWST is able to inject in BS-C, the RCS pressurizes above IRWST injection pressure during a short period producing a short cut off in IRWST injection and therefore a rise in PCT, Figs. 28 and 29. This behavior is not predicted in the modified sequence because when the IRWST starts to inject, the RCS is not 


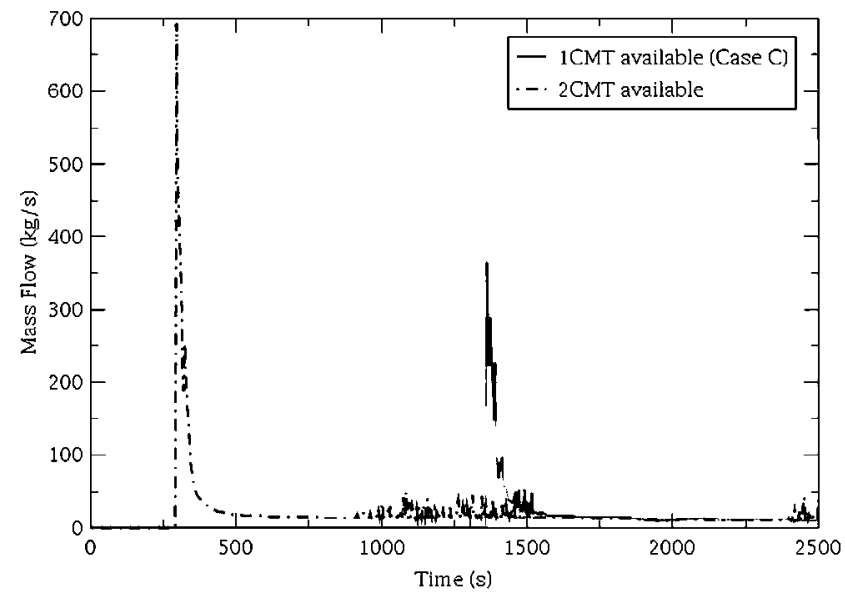

Fig. 26. ADS-4 mass flow (BS-C). Sensitivity to CMT availability.

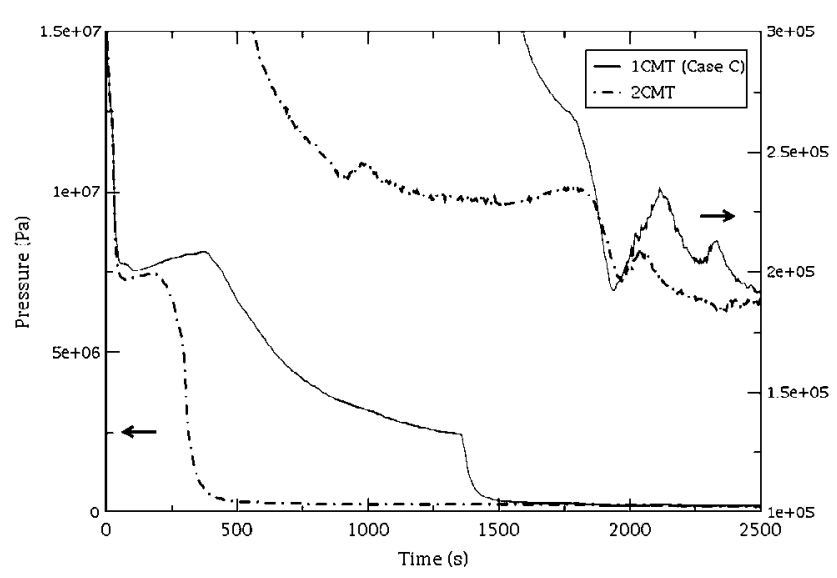

Fig. 27. RCS pressure (BS-C). Sensitivity to CMT availability.

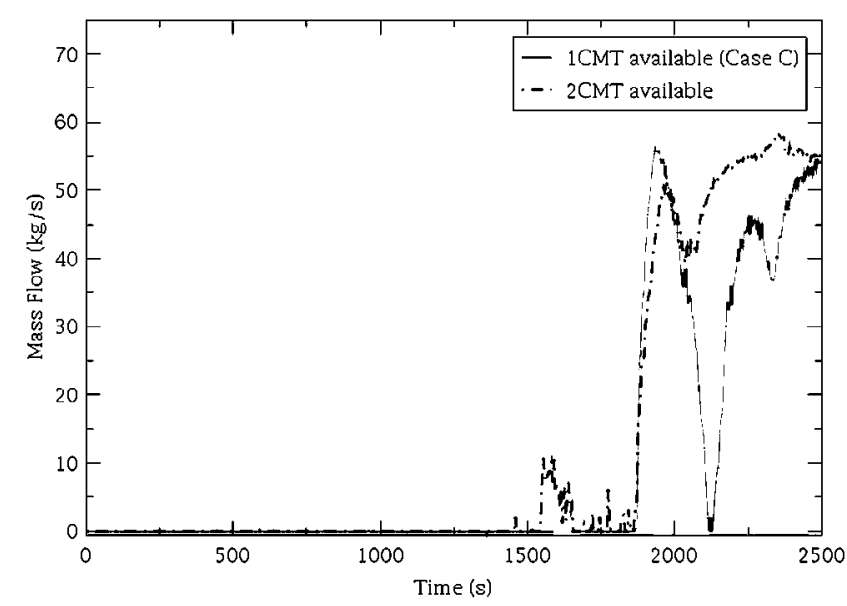

Fig. 28. IRWST injection (BS-C). Sensitivity to CMT availability.

pressurized as in BS-C and therefore the IRWST injection remain providing water in a suitable way.

Concerning to the core level, due to the earlier depressurization produced in the modified BS-C sequence because of ADS demand, the core level reaches a minimum close to $20 \%$ and stabilizes afterwards at $40 \%$, Fig. 30 . In BS-C, the core level decreases quickly

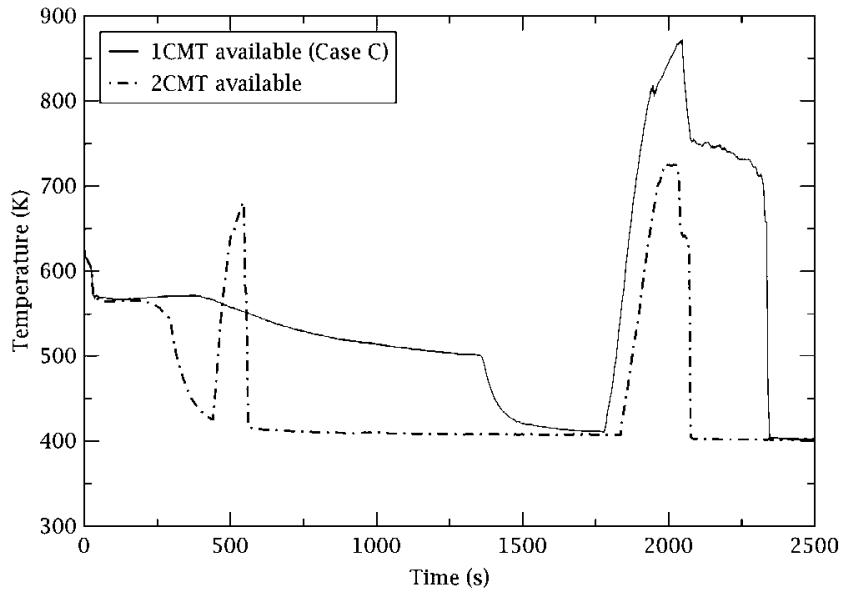

Fig. 29. PCT (BS-C). Sensitivity to CMT availability.

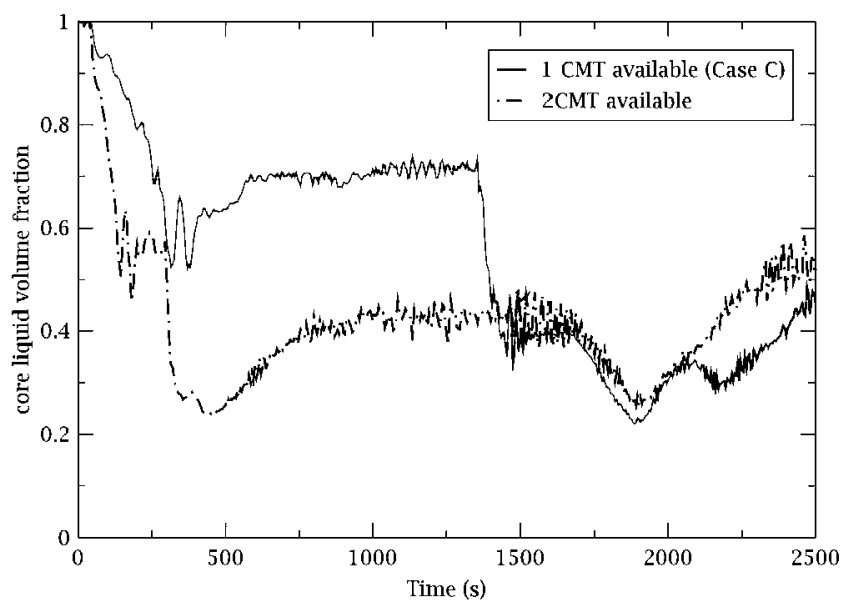

Fig. 30. Core Level (BS-C). Sensitivity to CMT availability.

Table 12

Sensitivity to CMT availability. Main events.

\begin{tabular}{lll}
\hline Event & BS-C & Modified BS-C \\
& 1 out of 2 CMT & 2 out of 2 CMT \\
\hline ADS actuation (s) & 1355.0 & 300.0 \\
CMT empties (s) & 1620.0 & 1550.0 \\
IRWST injection starts (s) & 1870.0 & 1860.0 \\
Minimum core level during blowdown (\%) & 55.0 & 25.0 \\
Maximum PCT $(\mathrm{K})$ & 871 & 726 \\
\hline
\end{tabular}

Table 13

Large Break LOCA (BS-D). Sequence chronology (TRACE code).

\begin{tabular}{ll}
\hline Event & Time $(\mathrm{s})$ \\
\hline Break occurs & 0.0 \\
S signal & 4.0 \\
CMT injection starts & 5.0 \\
RCP trip & 10.0 \\
CMT injection paused & 14.0 \\
ACC injection starts & 14.0 \\
PCT occurs & 50.0 \\
CMT injection resumed & 250.0 \\
IRWST injection & 1210.0 \\
\hline
\end{tabular}


when the ADS- 4 is automatically actuated at $1200 \mathrm{~s}$, then the core level is similar in both cases and stabilizes at 50\% providing long term cooling. Table 12 collects main events of both sequences.

These sensitivity analysis results, Table 12 , allow to confirm that BS-C is actually more limiting than the proposed modified $\mathrm{BS}-\mathrm{C}$ sequence.

\subsection{DEGB in cold leg. Low-margin bounding sequence D (BS-D)}

BS-D sequence presents the following safety systems availability: 2 out of CMTs, 2 out of 2 ACCs and 1 out of 2 IRWST injection lines. This sequence, DEGB in cold leg, is analysed in the AP1000 DCD chapter 15 by means of the best-estimate plus uncertainty ASTRUM methodology with WCOBRA/TRAC code, which corresponds to a SSG-2 option 3 methodology, see (Westinghouse Electric Company, 2008; US Nuclear Regulatory Commission, 2007) for more details. The differences between DCD LBLOCA best-estimate case and BS-D are, see (Westinghouse Electric Company, 2003b) section 15.0.12.3 and (Westinghouse Electric Company, 2003a),

- Offsite power is available until the RCPs are tripped in BS-D, but DCD case includes loss of offsite power at the time of the break and then RCPs are also tripped at the time of the break.

- DCD LBLOCA single failure hypothesis: One CMT valve fails to open. However, BS-D configuration includes 2 out of 2 CMTs available.

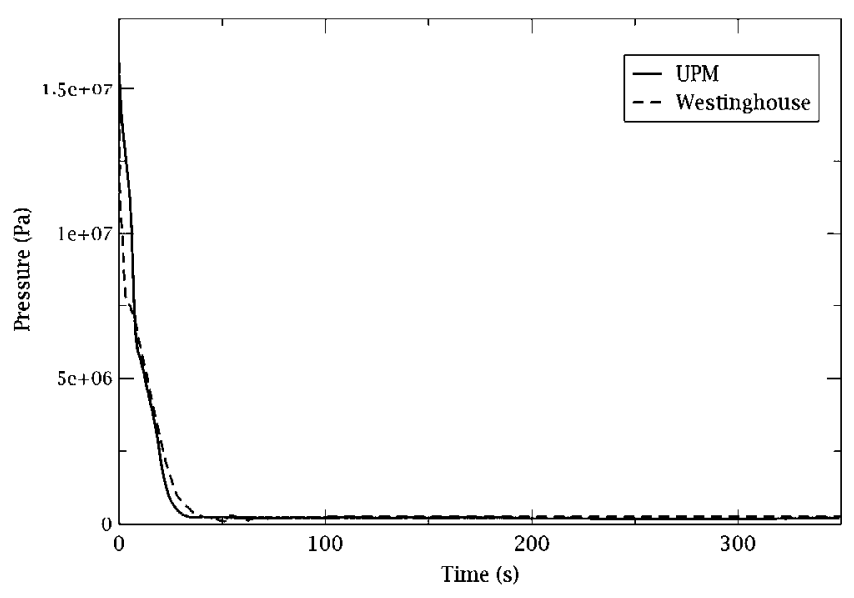

Fig. 31. RCS pressure (DEGB in cold leg, BS-D).

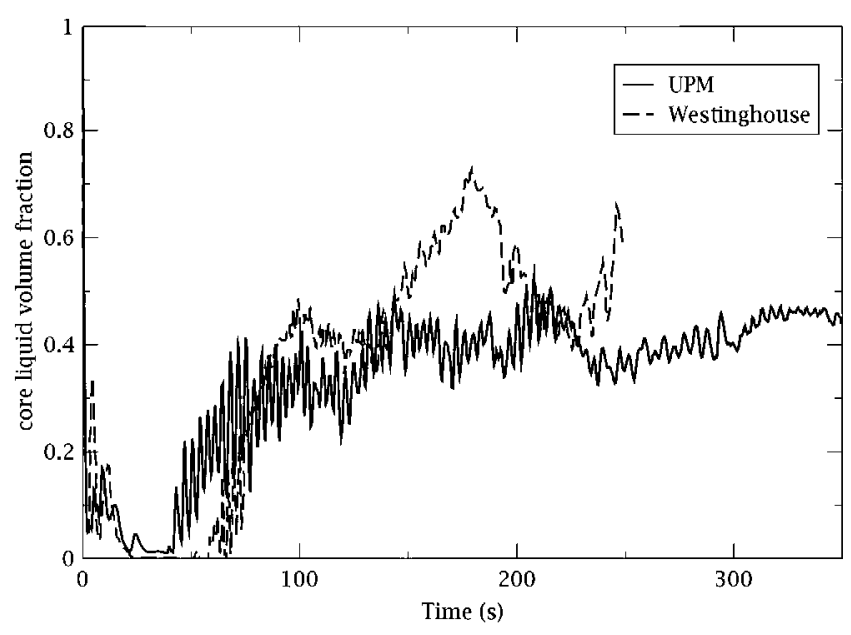

Fig. 32. Core Level (DEGB in cold leg, BS-D).
- The containment isolation is failed in BS-D, so that the containment is at atmospheric pressure.

The UPM group has simulated this sequence based on the same methodology and conservative hypotheses used for the other bounding sequences (SSG-2 option 2).

TRACE results are plotted comparing with those obtained by WEC with WCOBRA/TRAC code and the chronology of the TRACE sequence is presented in Table 13 (WCOBRA/TRAC chronology is not available in open literature). As it can be seen in Figs. 31-34, the predicted behavior is quite similar for both codes. One of the differences that can be appreciated corresponds to core level stabilization when such level is recovered, Fig. 32, which remains lower in the case of UPM. This fact produces the need of $100 \mathrm{~s}$ more to achieve successful core cooling in the hottest rod, Fig. 33. In both cases, the PCTs are far away from the acceptance criterion. WEC predicted for BS-D a best-estimate PCT value of $1159 \mathrm{~K}$ and then estimated the 95th percentile by adding the difference between:

- DCD LBLOCA analysis best-estimate reference case (1308 K)

- DCD LBLOCA result with uncertainty (1435 K).

Such difference $(1435-1308=127 \mathrm{~K})$ is added to BS-D bestestimate value to estimate the 95th percentile, $1286 \mathrm{~K}$ (Westinghouse Electric Company, 2003a). It must be noted that the maximum value for 95th percentile PCT in WEC case $(1286 \mathrm{~K})$ is slightly greater than the value obtained by UPM (1234 K)

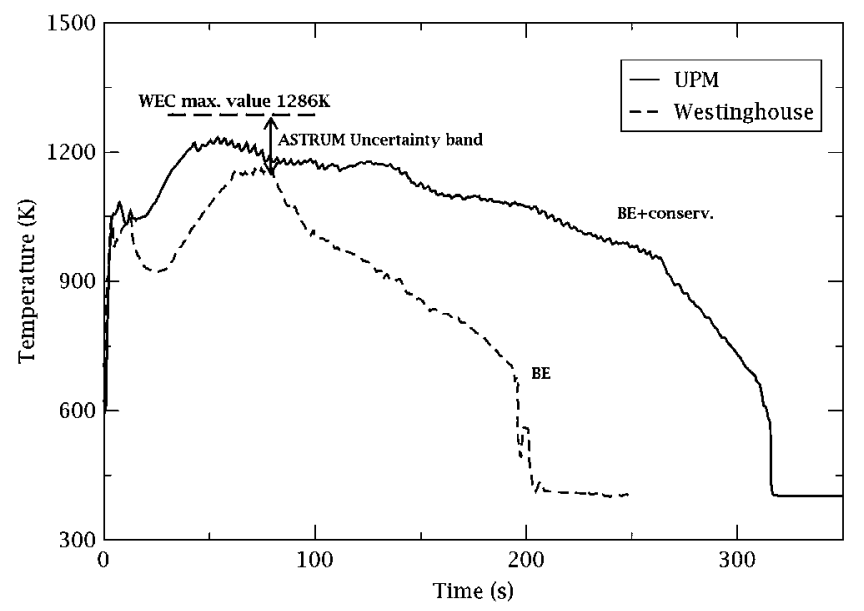

Fig. 33. PCT (DEGB in cold leg, BS-D).

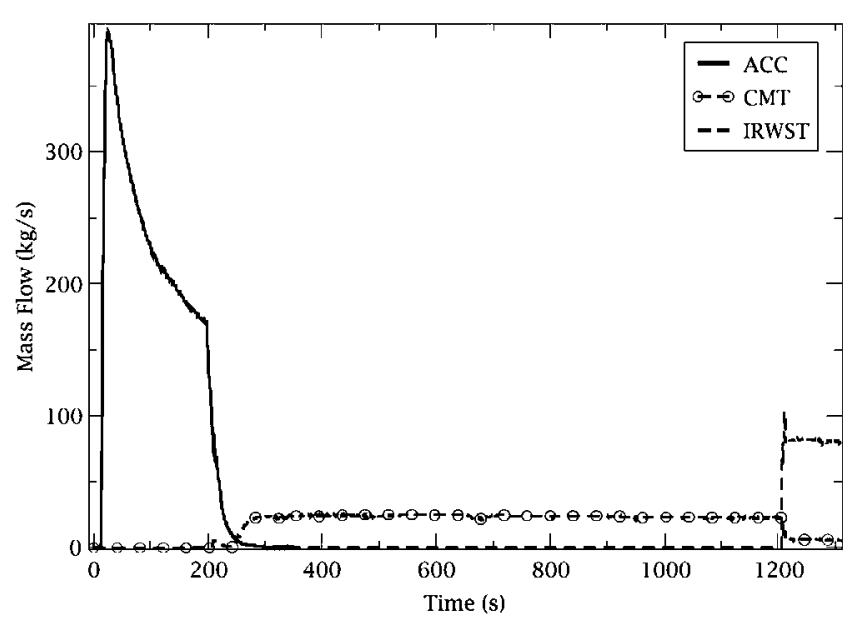

Fig. 34. Passive safety systems injection (DEGB in cold leg, BS-D). Extended view. 
6.5. Spurious ADS-4 actuation. Low-margin bounding sequence E (BSE)

BS-E sequence presents the following safety systems availability: 1 out of 2 CMTs, no ADS-1/2/3, 1 out of 2 ACCs, IRWST injection and PRHR actuation, Fig. 35. This case was analysed by WEC with the best-estimate WCOBRA/TRAC computer code (Zhang et al., 1998) and considering similar hypotheses and methodology as the ones for BS-D.

TRACE results are plotted comparing with those obtained by WEC with WCOBRA/TRAC code and the chronology of the TRACE sequence is presented in Table 14. Regarding the comparison of results between both codes, a very similar trend is obtained for the main variables. The pressure reaches the ACC pressure injection almost at the same time in both simulations, Fig. 36, although the discharge ends slightly later in case of WCOBRA/TRAC, Fig. 37. As it can be appreciated in Fig. 38, after ACC injection the core level is recovered and is maintained with the actuation of CMT and IRWST, Fig. 40. Finally, the PCT obtained in both analysis is quite similar, Fig. 39. It must be noted that, in the same way of BS-D sequence, WEC predicted for BS-E a best-estimate PCT value of $718 \mathrm{~K}$ and then the estimated 95 th percentile by adding the previous difference obtained for BS-D. Such difference $(127 \mathrm{~K})$ is added to the best-estimate BS-E value obtaining the mentioned $845 \mathrm{~K}$ (Westinghouse Electric Company, 2003a). This 95\% percentile PCT value is greater than PCT value obtained with TRACE (701 K).

6.6. Main results obtained in low-margin bounding sequences analysis with TRACE

The PCT obtained in short-term low-margin bounding sequences with TRACE using SSG-2 option 2 along with the ones for WEC using SSG-2 options 1 and 3 are collected in Table 15. The comparison allows verifying the results predicted by WEC by using different $\mathrm{T} / \mathrm{H}$ codes, NOTRUMP $(\mathrm{N})$ and WCOBRA/TRAC (WC/T). In general the PCT predicted with TRACE when there is
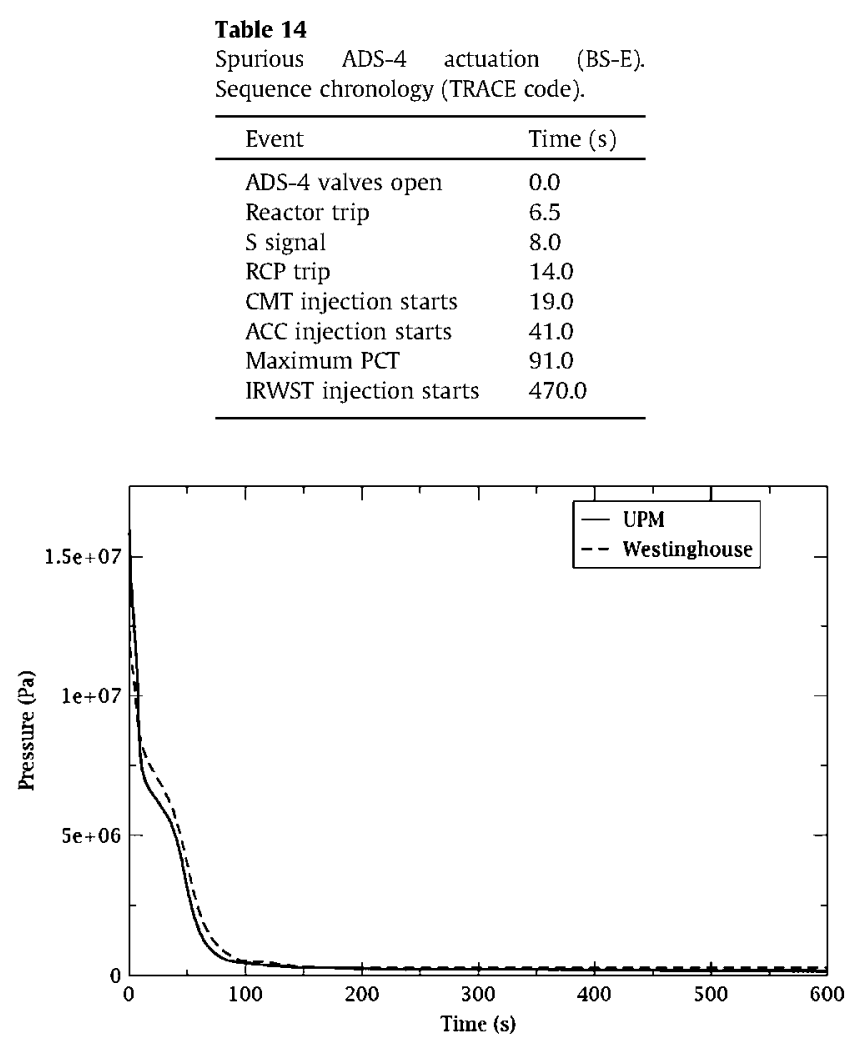

Fig. 36. RCS pressure (Spurious ADS-4 actuation, BS-E).

core uncovery is very similar to WEC results with exception of $B S-C$. Moreover no core uncovery is obtained with TRACE for BS$A$ and BS-B. It must be noted, that all these BS-k sequences where core uncovery sequences when they were simulated with MAAP. This result also indicates that the use of MAAP seems to be adequate for AP1000 PRA Level 1.

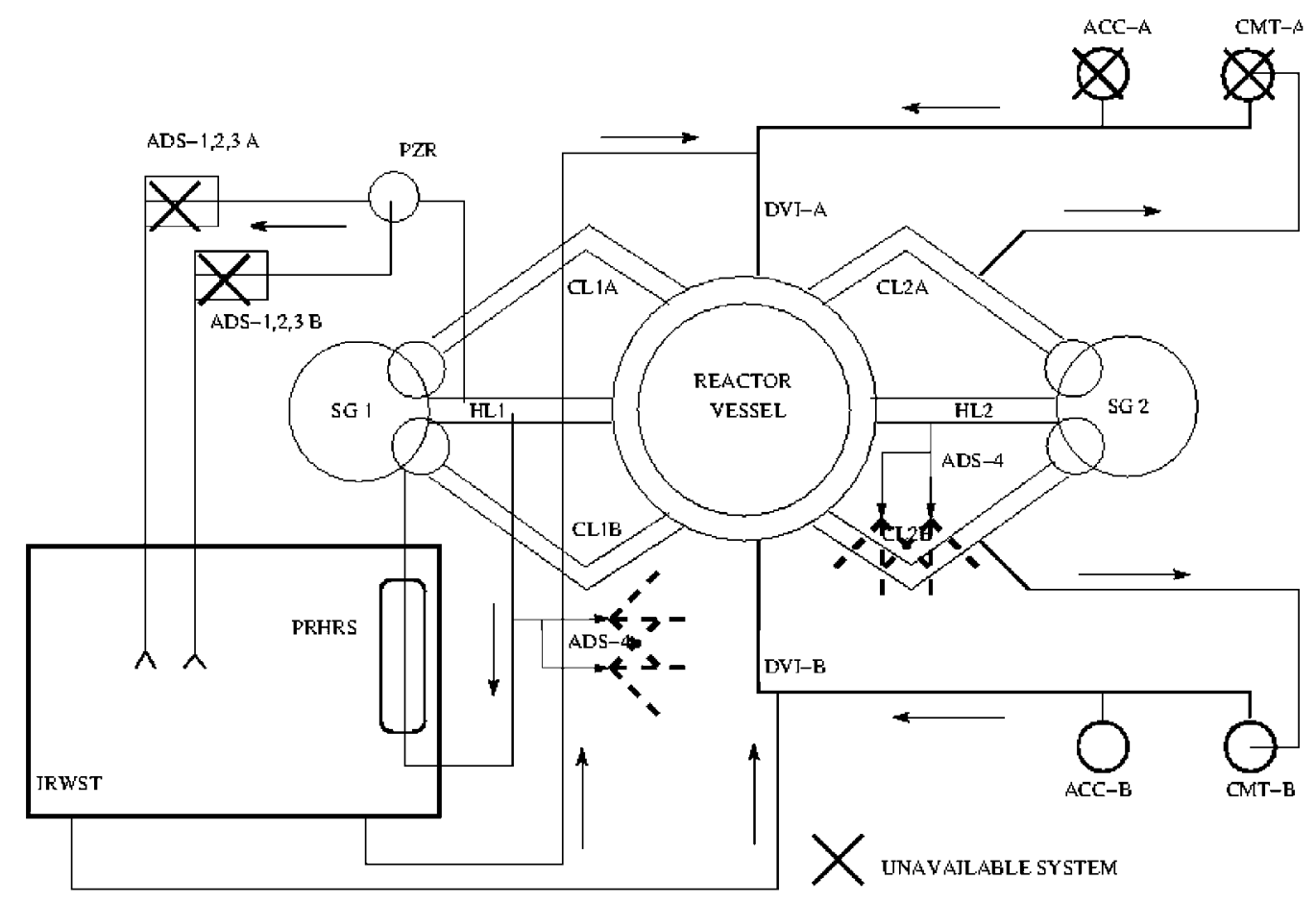

Fig. 35. Spurious ADS-4 actuation (BS-E). Availability of safety systems. 


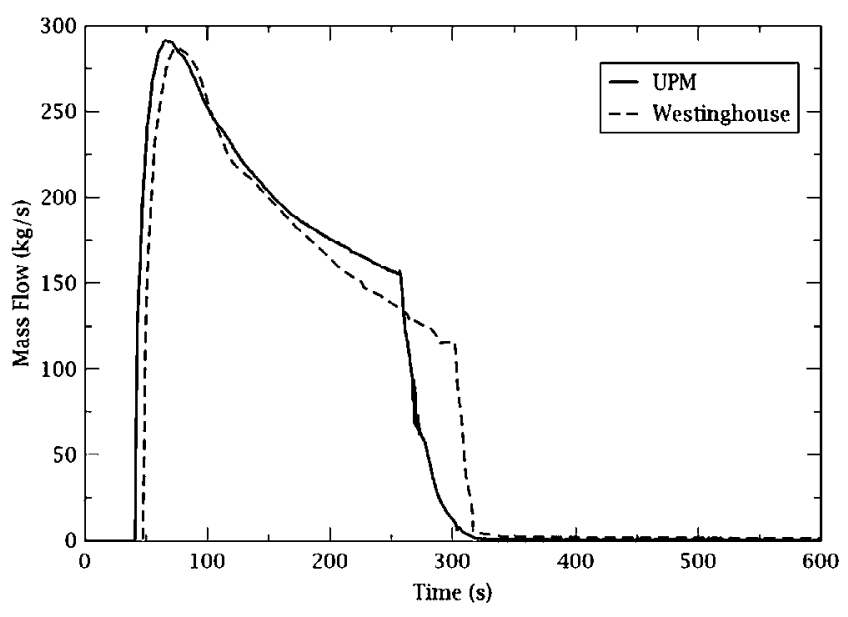

Fig. 37. ACC injection (Spurious ADS-4 actuation, BS-E).

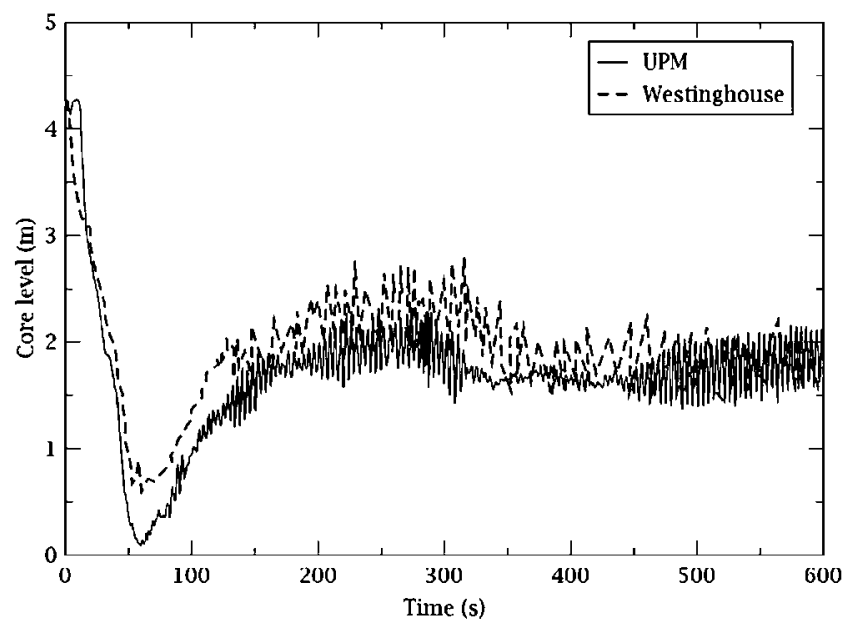

Fig. 38. Core level (Spurious ADS-4 actuation, BS-E).

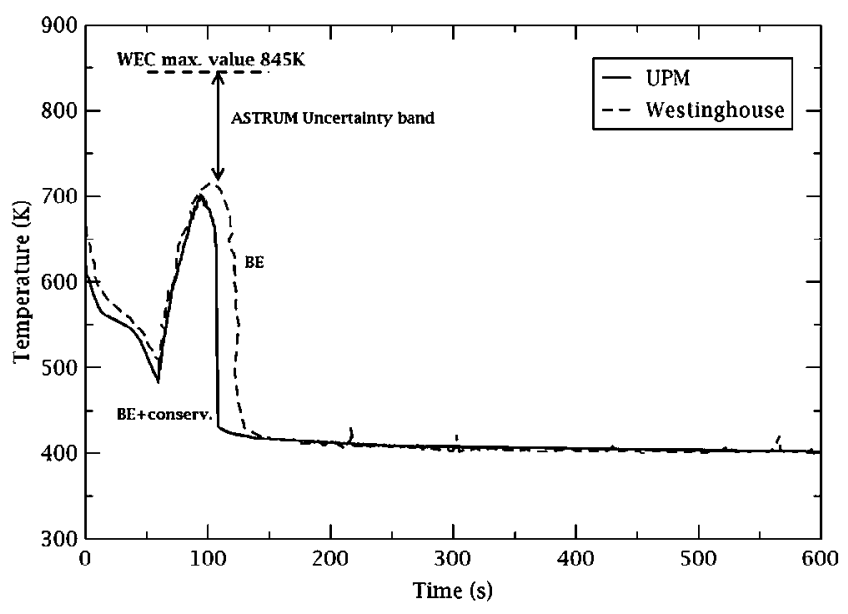

Fig. 39. PCT (Spurious ADS-4 actuation, BS-E).

\section{Conclusions}

This paper summarizes and verifies, the low-margin sequences evaluation process developed by WEC in order to bound the $\mathrm{T} / \mathrm{H}$ uncertainties that can affect to the PRA success criteria. Moreover, this study has verified with the best-estimate TRACE computer code, by means of SSG-2 option 2, the low-margin bounding

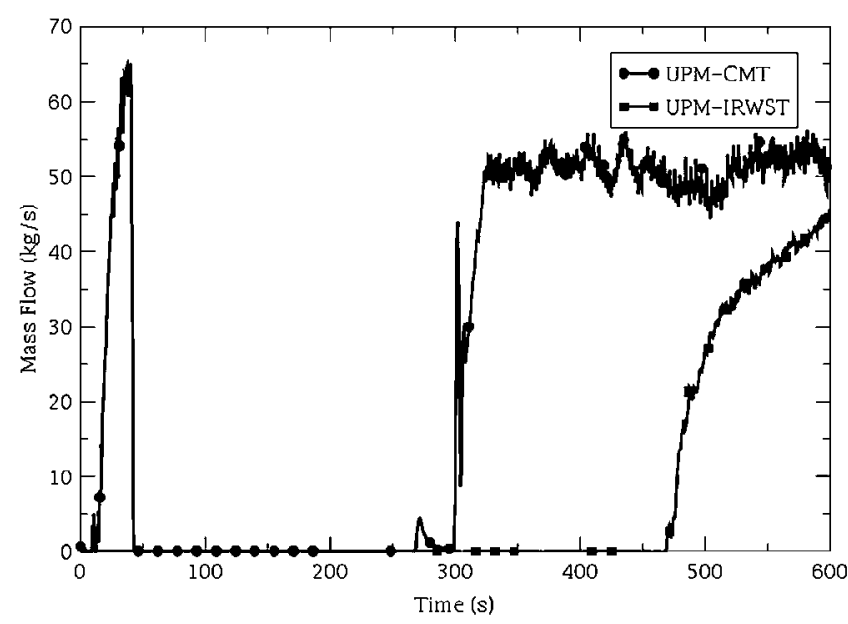

Fig. 40. CMT and IRWST mass flow (Spurious ADS-4 actuation, BS-E).

Table 15

Main results obtained for PCT in BS-k sequences. Comparison with WEC results.

\begin{tabular}{lll}
\hline Initiating event & TRACE (K) & WEC (K) \\
\hline Hot leg break (BS-A) & No core uncovery & $670(\mathrm{~N})$ \\
DEGB in CMT balance line (BS-B) & No core uncovery & No core uncovery (N) \\
DEGB in DVI line (BS-C) & 871 & $1127(\mathrm{~N})$ \\
DEGB in cold leg (BS-D) & 1234 & $1286(\mathrm{WC} / \mathrm{T})$ \\
Spurious ADS-4 actuation (BS-E) & 701 & $845(\mathrm{WC} / \mathrm{T})$ \\
\hline
\end{tabular}

sequences identified and evaluated by WEC using NOTRUMP (BSA, BS-B and BS-C) and WCOBRA/ TRAC (BS-D and BS-E).

The results show a similar trend between TRACE-NOTRUMP and TRACE-WCOBRA/TRAC. However, some differences are observed in the discharge of IRWST for small break sizes ( 3 in. hot leg break) in which NOTRUMP presents mass flow rate values which are almost a half of the predicted by TRACE. Such behavior was also observed in Friend et al. (1997) where this issue was analyzed in deep and the main reason for this behavior is the sensitivity of IRWST capacity to inject close to atmospheric conditions. Regarding the sequences in which core uncovery is found, the analysis show that a lower PCT value is always obtained in TRACE simulations with SSG-2 option 2. Nonetheless, all of them remain well below from the PCT acceptance criterion (1477 K).

As a global conclusion, this analysis has allowed to verify the AP1000 T/H uncertainty evaluation process performed by WEC for the most risk-important low-margin sequences with a bestestimate code such as TRACE applying SSG-2 option 2 approach.

This work has allowed enlarging the set of DSA and PRA verifications related with different AP1000 sequences by means of TRACE code in the framework of the ISAMAR project. New PRA and DSA verification analyses will be performed in future works.

\section{Disclaimer}

This paper is the result of the analysis carried out by the research group of the Technical University of Madrid and therefore Westinghouse Electric Company and the USNRC were not involved in such investigations and they are not responsible about the contents here exposed.

AP1000 is a trademark or registered trademark in the United States of Westinghouse Electric Company LLC, its subsidiaries and/or its affiliates. This mark may also be used and/or registered in other countries throughout the world. All rights reserved. Unauthorized use is strictly prohibited. Other names may be trademarks of their respective owners. 


\section{Acknowledgements}

This work has been funded by the Spanish Ministry of Competitiveness and Economy within ISAMAR project: ENE2011-28256. Its support is gratefully acknowledged. The authors would also like to thanks to Westinghouse Electric Company and to USNRC for the technical support.

\section{References}

Advisory Committee on Reactor Safeguards subcommittees on Reliability and probabilistic Risk Assessment. Official Transcript of proceedings ACRST-3228. NRC. 23, January 2003.

Friend, M.T., Wright, R.F., Hundal, R., Hochreiter, L.E., Ogrins, M., 1997. AP600 response to small break loss of coolant accident events: Analysis of SPES-2 integral test results. Nucl. Technol. 122, 19-42.

Hochreiter, L.E., et al. WCOBRA/TRAC Applicability to AP600 Large-Break Loss-ofCoolant Accident, WCAP-14171, Revision 2 (Proprietary) and WCAP-14172, Revision 2 (Non proprietary), March 1998.

IAEA, 2009. IAEA Specific Safety Standards for protecting people and the environment, Deterministic Safety Analysis for Nuclear Power Plants, Specific Safety Guide No. SSG-2.

Lafi, A.Y., Reyes, J.N. Two-inch Cold Leg Break Tests in APEX and ROSA/AP600Comparative Study. In: 9 th International Topical Meeting on Nuclear Reactor Thermal Hydraulics (NURETH-9). California, San Francisco, 1999.

Lime, F.J., Boyack, B.E., Updated TRAC Analysis of an AP600 Design. Technical Report LA-UR-94-121, Los Alamos National Laboratory, February 1994.

MAAP4, Modular Accident Analysis program for LWR Power plants. Computer Code User's Manual. Electric Power Research institute, 1994.

Meyer, P.E., "NOTRUMP - A Nodal Transient Small-Break and General Network Code", WCAP-10079-P-A (Proprietary) and WCAP-10080-A (Non proprietary), August 1985.
Montero-Mayorga, J., Queral, C., Gonzalez-Cadelo J., 2014. Analysis and Verification of Direct Vessel Injection Line Break event tree for AP1000 ${ }^{\circledR}$ reactor with TRACE code. Nuclear España, no 356

Montero-Mayorga, J., Queral, C., Gonzalez-Cadelo J., 2015. AP1000 SBLOCA simulations with TRACE code. Annals of Nuclear Energy, Volume 75, January 2015, pp. 87-100.

Ohkawa et al. "AP600 PRA Thermal/Hydraulic Uncertainty Evaluation for Passive Systems Reliability". WCAP-14800-NP. Westinghouse Electric Company. June 1997.

Queral, C., Montero-Mayorga, J., 2016. Risk reduction due to modification of normal residual heat removal system of $\mathbf{A P 1 0 0 0}^{\circledR}$ reactor to meet European Utility Requirements, Annals of Nuclear Energy, Volume 91, May 2016, pp. 65-78.

Queral, C., Montero-Mayorga, J., Gonzalez-Cadelo, J., Jiménez, G. 2015. AP1000 Large-Break LOCA BEPU analysis with TRACE code. Annals of Nuclear Energy, Volume 85 , November 2015, pp. 576-589.

Selim Sancaktar and Terry Schulz. Risk Informing PRA Success Criteria. In: Application to the AP1000 Proceedings of ICAPP '04 Pittsburgh, PA, USA, June 13-17, 2004 Paper 4239.

Shimeck D.J., Hartz J.J. Description of the Westinghouse LOCTAJR 1-D Heat Conduction Code for LOCA Analysis of Fuel Rods. WCAP-15578 (Non proprietary), September 2000.

US Nuclear Regulatory Commission. TRAC-RELAP Advanced Computational Engine (TRACE) User's Manual Input Specification. 2007

Westinghouse Electric Company. “AP1000 Probabilistic Risk Assessment Report. Chapter 59 Appendix A. Thermal Hydraulic analysis to Support Success Criteria". AAN: ML030510639. 2003a.

Westinghouse Electric Company. MAAP4/NOTRUMP Benchmarking to Support The Use of MAAP4 for AP600 Success Criteria Analysis, WCAP-14869, 1997.

Westinghouse Electric Company. AP1000 Probabilistic Risk Assessment Report. $2003 \mathrm{~b}$.

Westinghouse Electric Company. AP1000 Design Control Document. Rev19. 2008

Wright, R.F., 2007. Simulated AP1000 response to design basis small-break LOCA events in APEX-1000 test facility. Nucl. Eng. Technol. 39, 287-298.

Zhang, J., Bajorek, S.M., Kemper, R.M., Nissley, M.E., Petkov, N., Hochreiter, L.E., 1998. Application of the WCOBRA/TRAC best-estimate methodology to the AP600 large-break LOCA analysis. Nucl. Eng. Des. 186, 279-301. 